\title{
Spectral analysis of water level fluctuations in aquifers
}

\author{
D. C.-F. Shih, G.-F. Lin
}

\begin{abstract}
The water level of a seawater gauging station and 18 groundwater wells coupled with atmospheric pressure in southwestern Taiwan are analyzed by using spectral analysis in time and frequency domain. The semidiurnal component is found to be the most significant signal from the measurement of water level and atmospheric pressure, and the diurnal component is less distinctive in part of water level and atmospheric pressure record. Although auto-spectral and crossspectral density functions are significant in atmospheric pressure and water level, the pressure variations do not significantly affect the seawater and the majority of groundwater level in the study area with amplitude of time series observations. The astronomical tidal components are likely the main factor causing seawater and groundwater level to fluctuate in Pingtung, Taiwan. Time lags are estimated from $20 \mathrm{~min}$ to a few hours in aquifers. It concludes that the disturbance on groundwater levels from the effect of oceanic astronomical tide is different from the varying hydrogeological characteristics of aquifer. In this study, the spectral analysis of water level in time and frequency domains gives strong indications of sensitive variations to water level fluctuation.
\end{abstract}

Keywords: Groundwater, Spectral analysis, Tide

\section{1}

\section{Introduction}

The water level data of five river stages and seven groundwater wells in Taipei Basin were analyzed by spectral analysis in time and frequency domains (Shih et al., 1999). In that study, the diurnal, semi-diurnal, and quarter-diurnal tidal components of Tanshui River appear to be closely related to astronomical tides as $K_{1}, M_{2}$, and $M_{4}$, respectively. The diurnal $K_{1}$ tide is lunisolar diurnal constituent.

D. C.-F. Shih ( $\square)$

Institute of Nuclear Energy Research, AEC,

P.O. Box 3-7, Lungtan, 325,

Taiwan, Republic of China

E-mail: cfshih@iner.gov.tw

G.-F. Lin

Department of Civil Engineering,

National Taiwan University, Taipei 10617,

Taiwan, Republic of China

This research is supported by the Institute of Nuclear Energy

Research (INER), AEC, Taiwan, Republic of China, under a fund

from Executive Yuan. The authors thank Taiwan Central Weather

Bureau and Taiwan Provincial Government Water Resources

Department for providing useful data. 
This constituent, with $O_{1}$, expresses the effect of the Moon's declination. They account for diurnal inequality and, at extremes, diurnal tides. With $P_{1}$, it expresses the effect of the Sun's declination. Its speed equals to $15.0410686^{\circ}$ per solar hour. The semidiurnal $M_{2}$ tide is principal lunar semidiurnal constituent. This constituent represents the rotation of the Earth with respect to the Moon. Its speed equals to $28.9841042^{\circ}$ per solar hour. The quarter-diurnal $M_{4}$ tide is a shallow water overtide of principal lunar constituent. Its speed equals to $57.9682084^{\circ}$ per solar hour. Shih et al. (1999) reports that these phenomena could be caused by the local variation of river channel topography. The diurnal component reveals a reversed phase angle in the middle section of Tanshui River; the phase of quarter-diurnal component is also reversed at stations in the upstream of Tanshui River and Hsintienhsi river. The autospectrum and cross-spectrum between groundwater elevation and nearby river stages were observed to highly correlate to the frequency of astronomical tide $K_{1}, M_{2}$, and $M_{4}$. From that study, the tidal effects of diurnal, semidiurnal, and quarter-diurnal components are significantly different. The water level data at sixteen groundwater wells and two sea water gauging stations, coupled with atmospheric pressure measurements in an alluvial plain in the central-west region of Taiwan, are analyzed by using spectral analysis in the time and frequency domains (Shih et al., 2000). The semidiurnal component in water level is observed to be the most noticeable signal while the diurnal component is the less distinct signal recorded at the water level stations. The spectral analysis indicates that both the raw, and the atmospheric pressure adjusted water levels are almost in phase and retain the same amplitude in this area. It implies that the effect of pressure variations is not significant for sea water and groundwater level nearby; the astronomical tidal components, as expected, are the main factor causing fluctuation of seawater and groundwater levels in Choshuihsi alluvial plain (Shih et al., 2000).

The purposes of this study are to analyze fluctuations of groundwater levels, seawater level, and nearby atmospheric pressure data in Pintung county, Taiwan. The results of spectral analysis in the study area are systematically described and the significance of fluctuations in water level is also discovered. Data of main astronomical tidal components (Godin, 1972) and atmospheric pressure characteristics are presented to demonstrate the tidal phenomena in this study.

\section{2}

\section{Background information}

In Fig. 1, the study area is located in southern Taiwan. Kaopinghsi, Tungkanghsi, and Linpienhsi rivers flow through the plain and enter to Taiwan Strait. Laonunghsi and Ailiaohsi, and Lilihsi rivers are in the north and south of plain, respectively. The water level data are collected from eighteen groundwater wells, one seawater level station (KOS), and one atmospheric pressure station (KOSp) for this study (Fig. 1 and Table 1). The construction well boring logs show the aquifer layer and the screen interval of the well (Table 1). The observed periodic fluctuations of water level and semi-diurnal band passed water level and clearly appear in most gauging stations (Fig. 2a-e). The oceanic topography data indicates the depth of sea floor reaches about $100 \mathrm{~m}$ at a distance $20 \mathrm{~km}$ from shoreline (Chinese Navy Chart, 1995). The studied aquifers were tapped by groundwater wells of TAC, TTN, NPU, FNL, TNK, KNT, and WNU are above the sea floor elevation while others are partly above or below sea bottom (Table 1). 


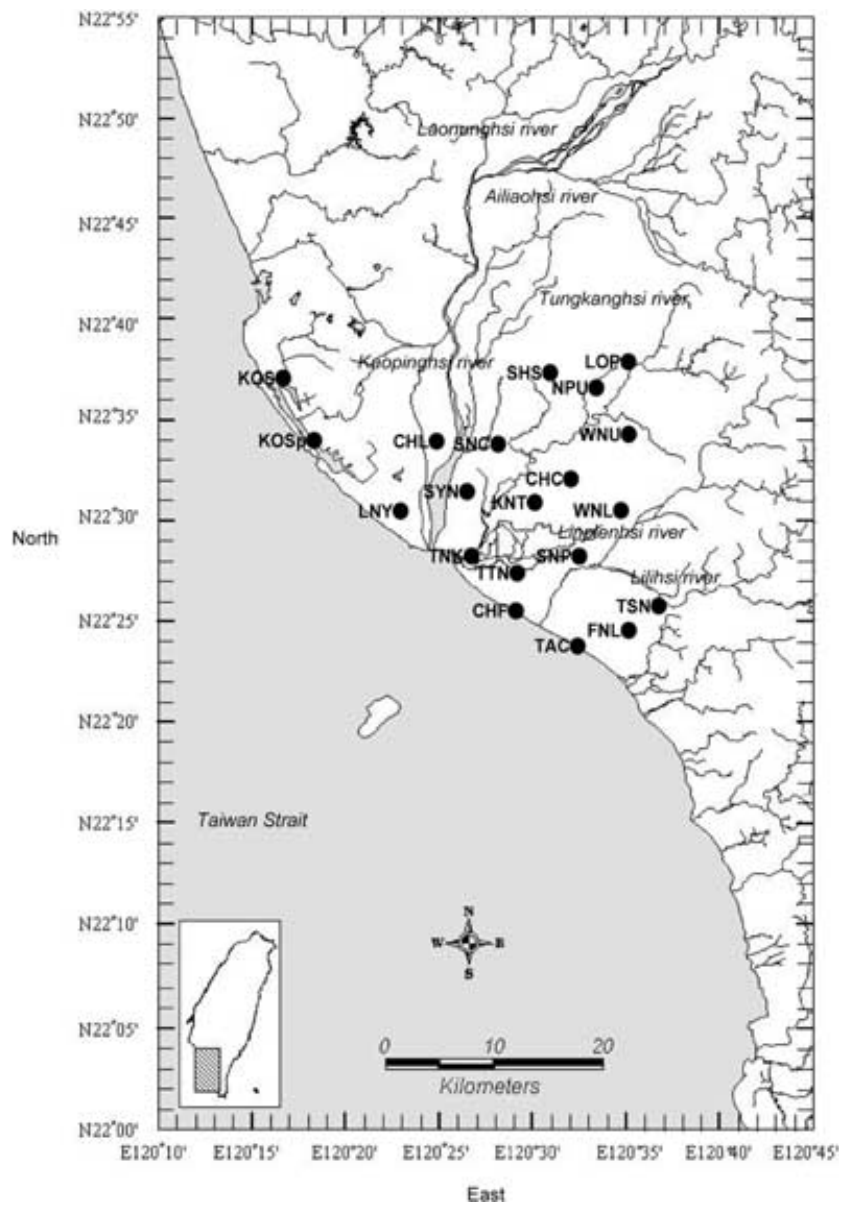

Fig. 1. Map of locations of groundwater well, seawater gauging station, and atmospheric pressure station in the Pingtung, Taiwan

\section{3}

\section{Spectral analysis}

Spectral analysis is an effective method to evaluate the characteristics of periodic wave motion in frequency domain (Bendat and Piersol, 1991; Shih et al., 1999; Shih, 1999a, b; Shih et al., 2000). The basic mathematical and statistical calculation procedures of spectral analysis are presented in this section as a review.

Considering a random variable in the time domain $x=x(t)$, the complex Fourier components in the frequency domain can be expressed as

$X(f)=\int_{-\infty}^{\infty} x(t) \mathrm{e}^{-2 \pi f t i} \mathrm{~d} t$

where $x$ is a random variable in the time domain; $t$ is the elapsed time; $f$ is cyclical frequency; $X$ is the complex Fourier components in the frequency domain; and $i$ is $\sqrt{-1}$ (Bendat and Piersol, 1991).

In a practical application, let the finite time be incorporated in Eq. (1), which can be rewritten as 


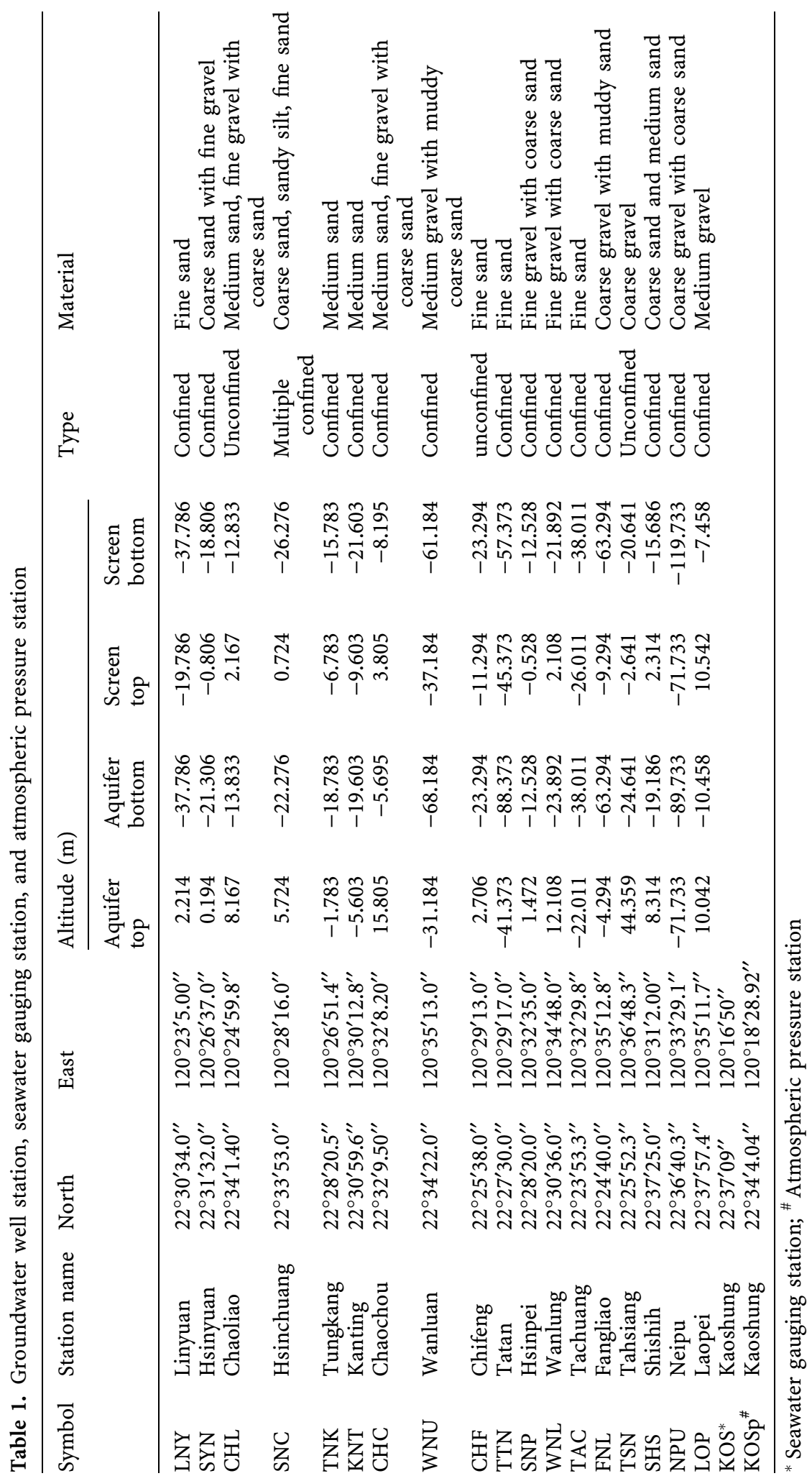


a
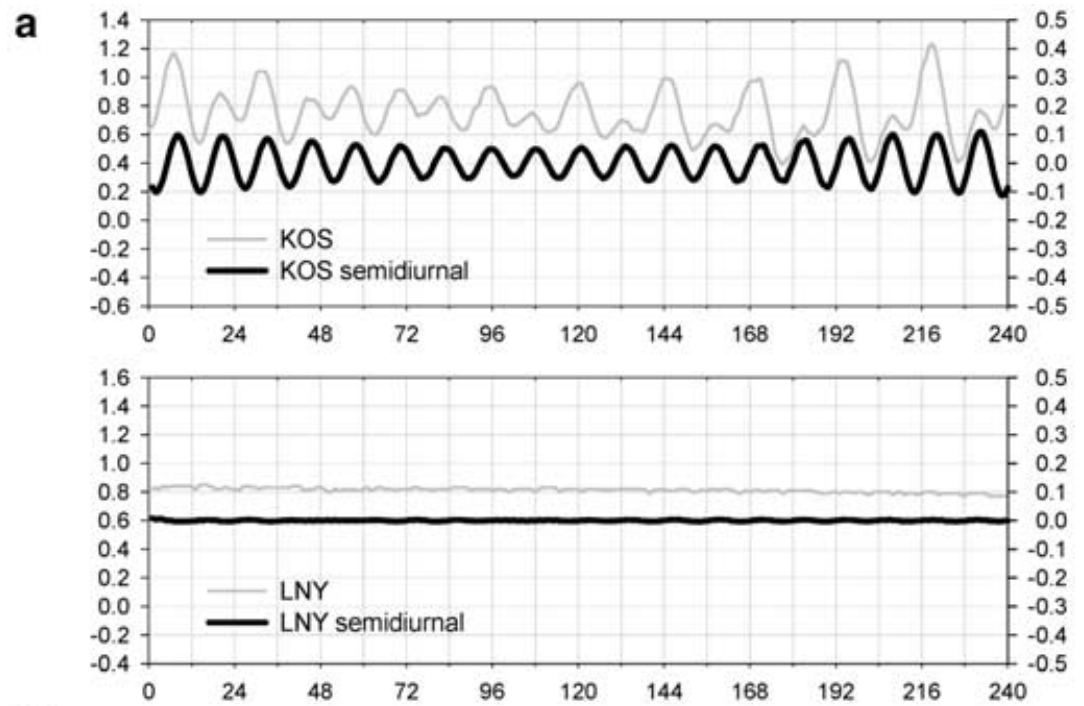

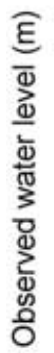
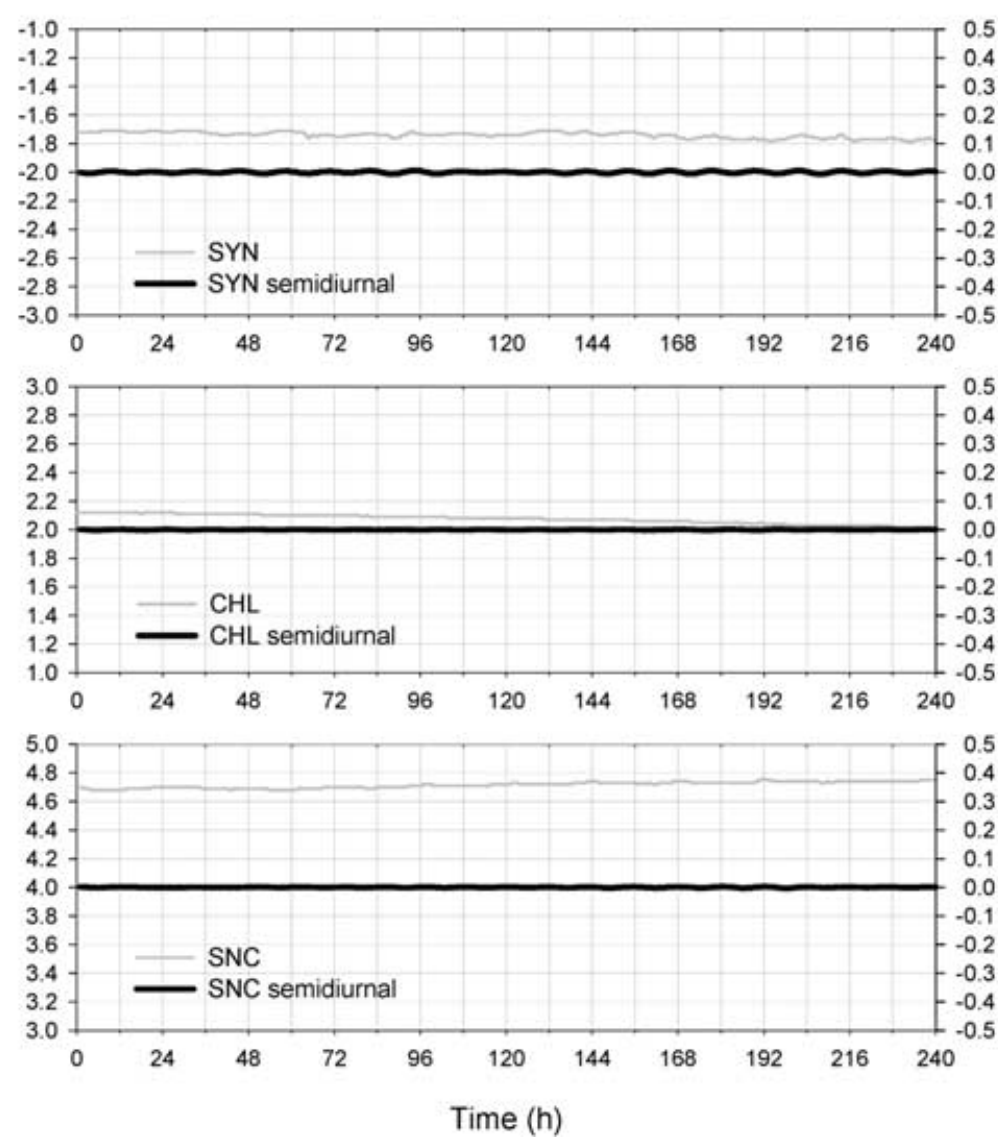

Fig. 2a-e. Time series of groundwater and seawater level. a KOS, LNY, SYN, CHL, SNC. b KOS, TNK, KNT, CHC, WNU. c KOS, CHF, TTN, SNP, WNL. d KOS, TAC, FNL, TSN. e KOS, SHS, NPU, LOP 

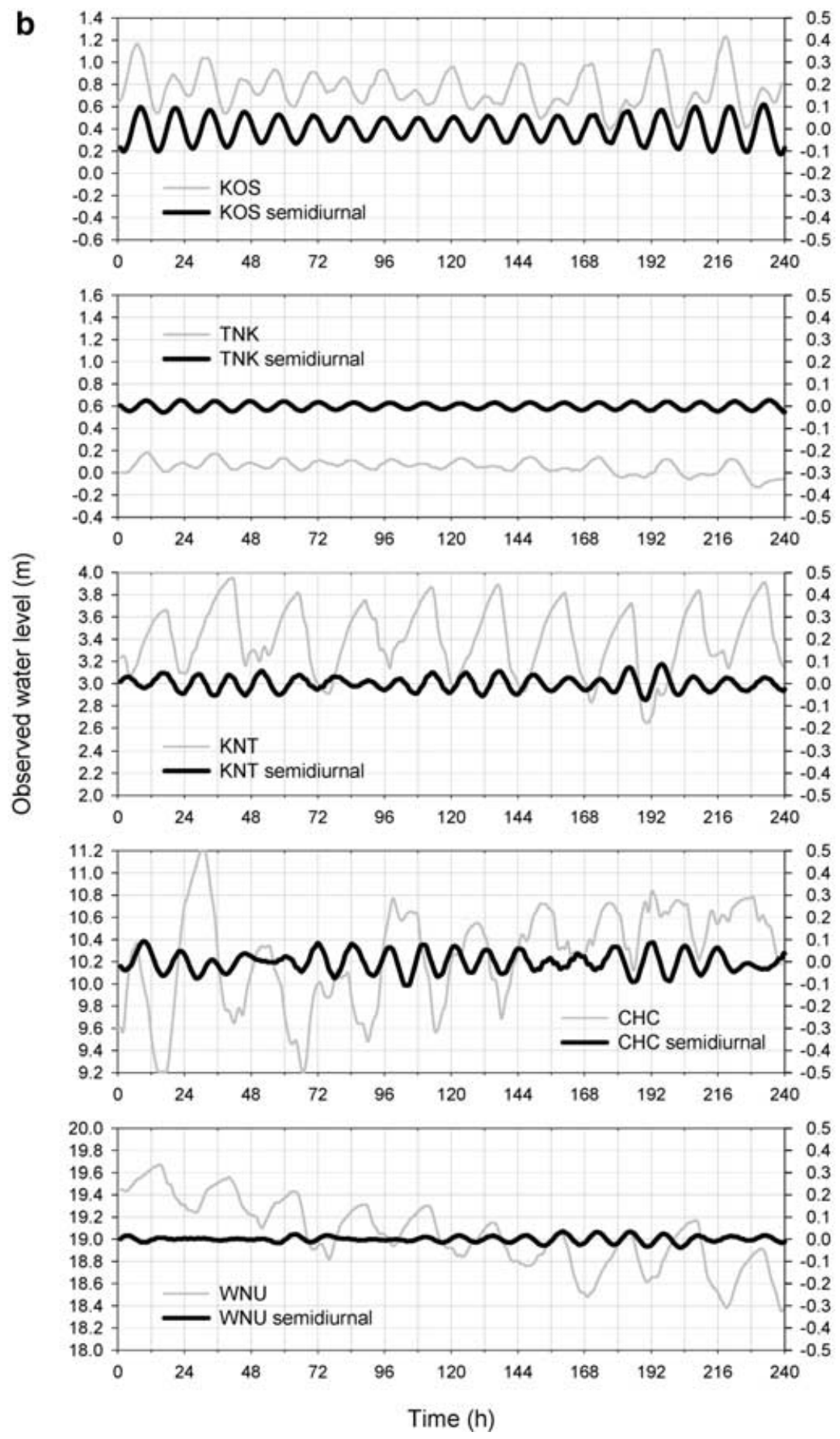

Fig. 2. (Continued) 
c
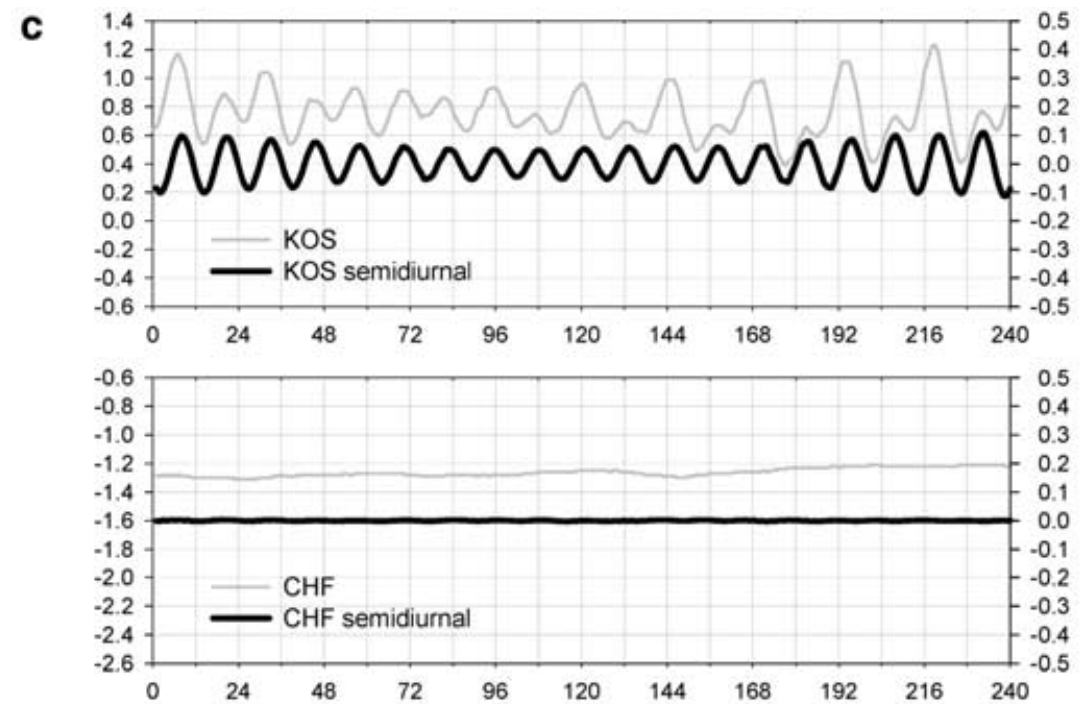

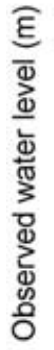
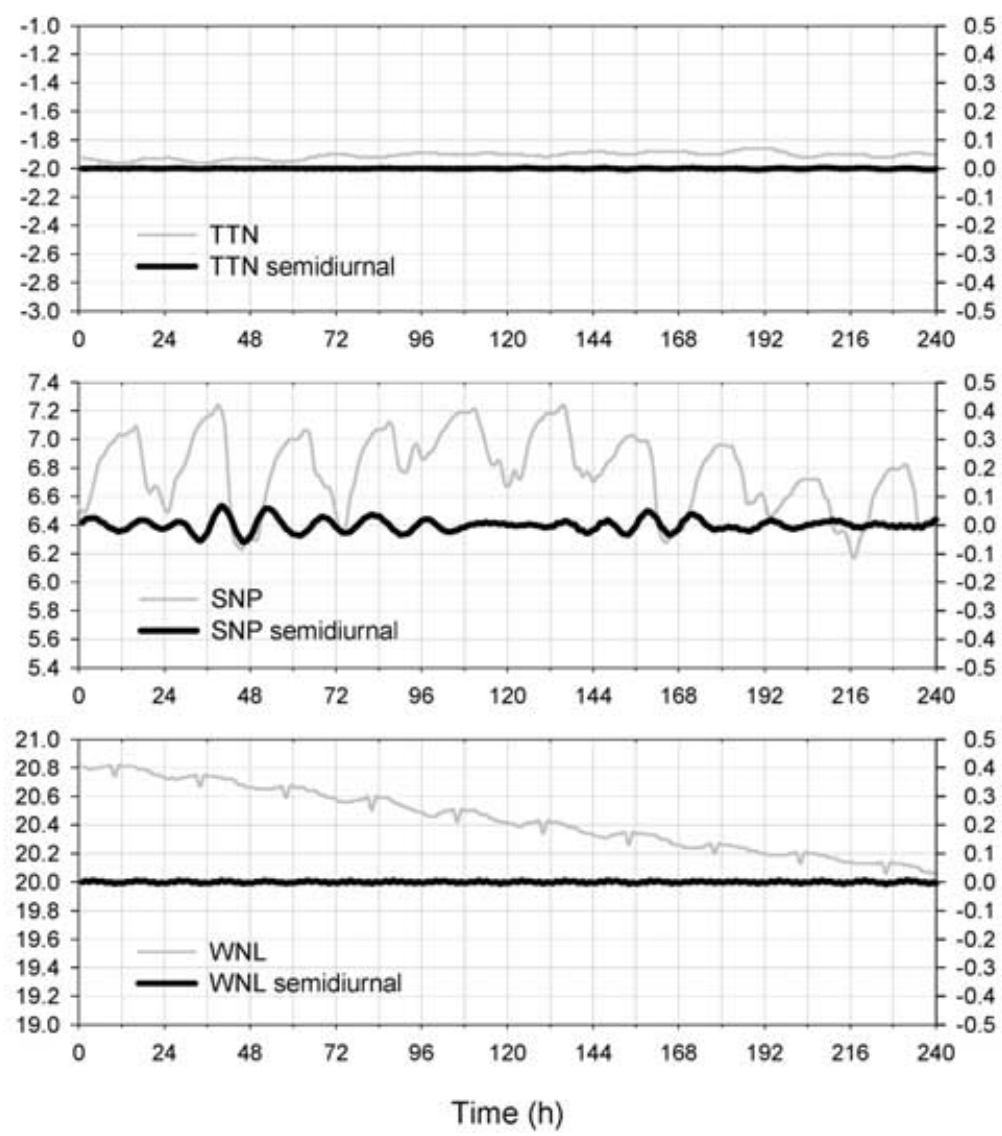

Fig. 2. (Continued) 

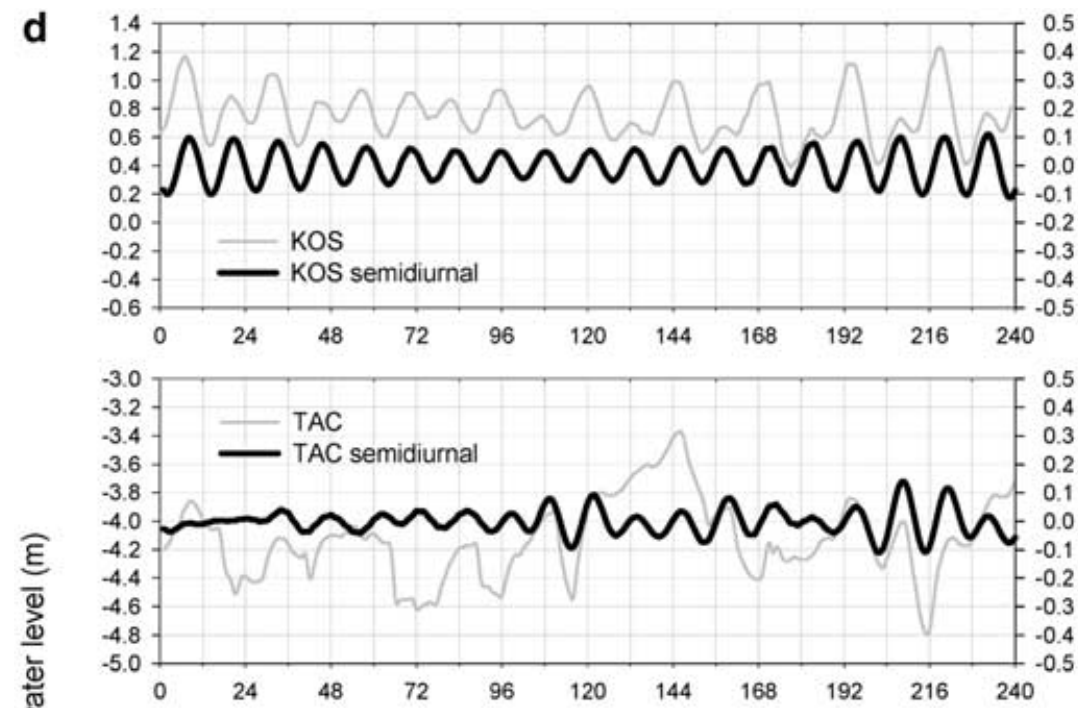

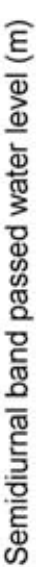
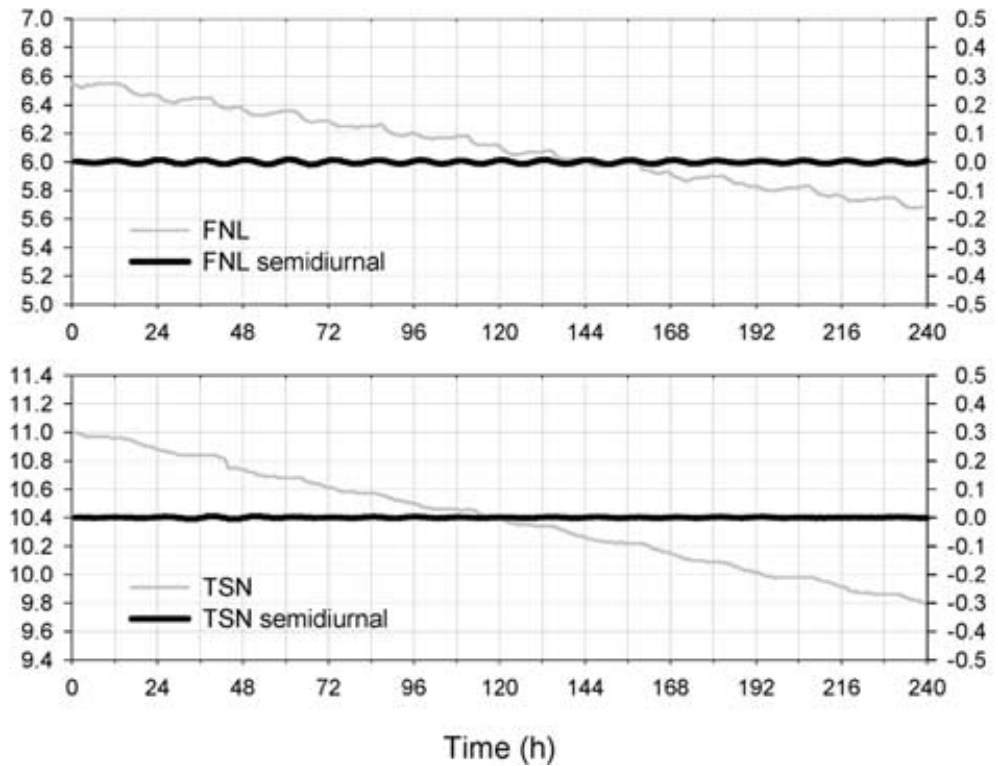

Fig. 2. (Continued)

$X(f, T)=\int_{0}^{T} x(t) \mathrm{e}^{-2 \pi f t i} \mathrm{~d} t$

where $T$ is a finite time interval.

The transformed component $X$ is not only a function of frequency but also of the finite time length. For a small time period, Eq. (2) cannot be satisfied due to the lack of statistical significance. As a result, the effect of related physical property of water level fluctuations is ignored.

Consider a stationary time series $x(t)$ of total length $T$, and let the time record be divided into $n_{d}$ contiguous segments, such as length $T_{s}$, it follows that a two- 

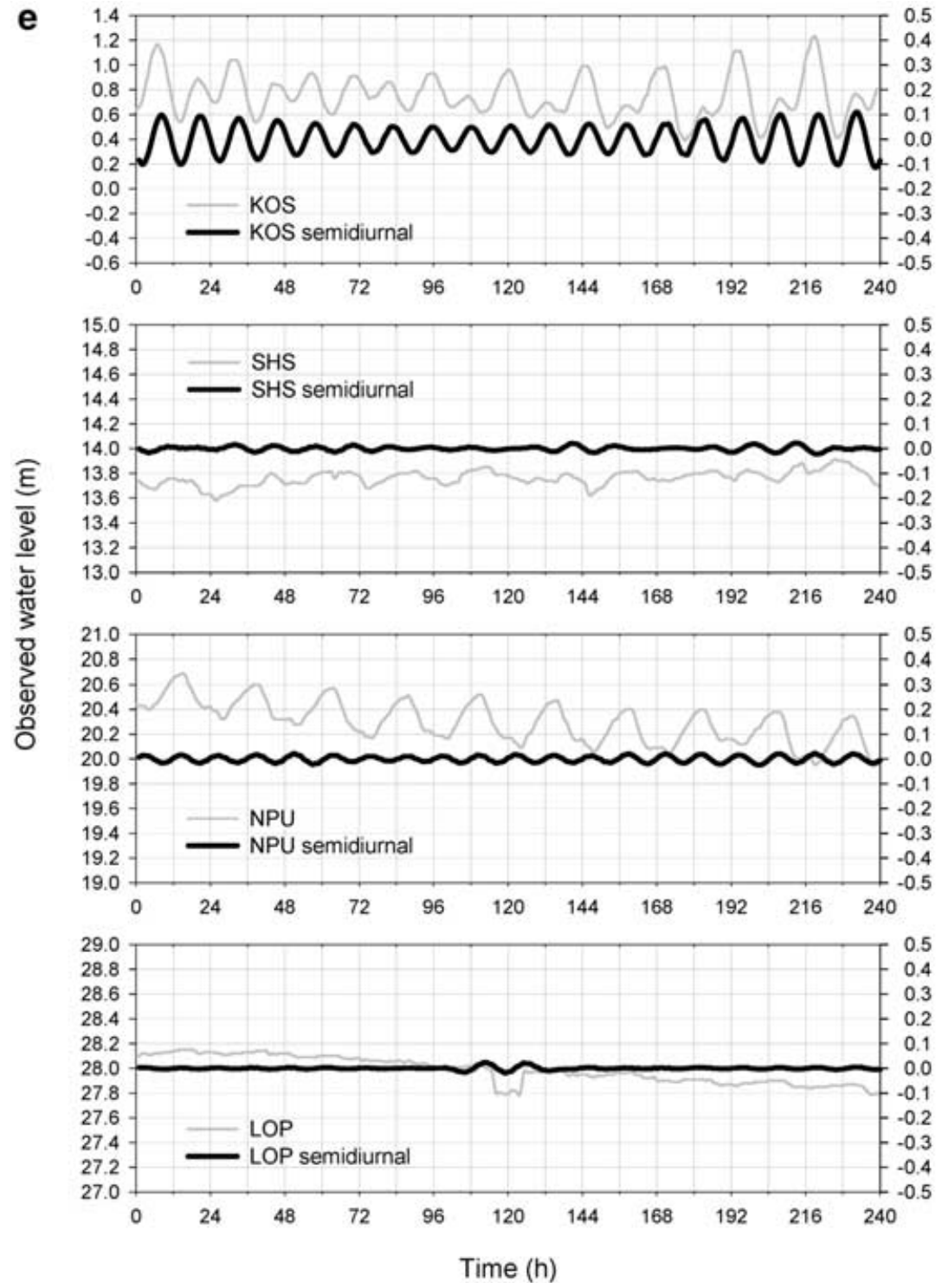

Fig. 2. (Continued)

sided autospectral density function (Bendat and Piersol, 1991) for each segment can be estimated by

$S_{x x}=\frac{1}{T_{s}}\left|X\left(f, T_{s}\right)\right|^{2}$

By averaging each of the resulting components, we obtain a final "smooth" component to be satisfied with required statistical significant level (Bendat and Piersol, 1991).

Given $\Delta t$ as the sampling rate in time domain, the discrete frequency is defined as 

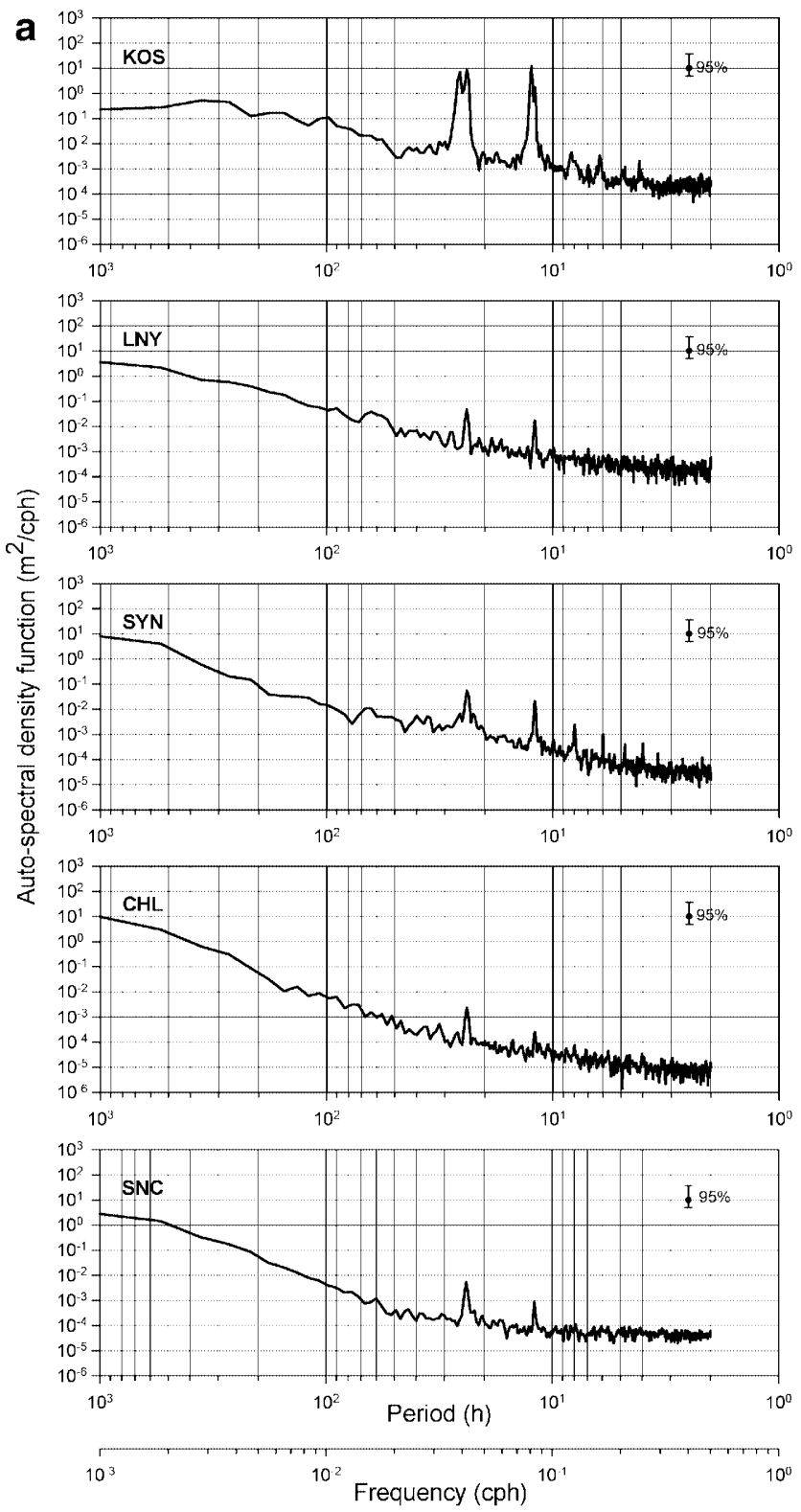

Fig. 3a-e. Auto-spectral density function of groundwater and seawater level. a KOS, LNY, SYN, CHL, SNC. b KOS, TNK, KNT, CHC, WNU. c KOS, CHF, TTN, SNP, WNL. d KOS, TAC, FNL, TSN. e KOS, SHS, NPU, LOP

$f_{k}=\frac{k}{T_{s}}=\frac{k}{N \Delta t} ; \quad k=0,1,2, \ldots, N-1$

where $N$ is the length of segments.

The smoothed, one-sided autospectral density function is expressed as 

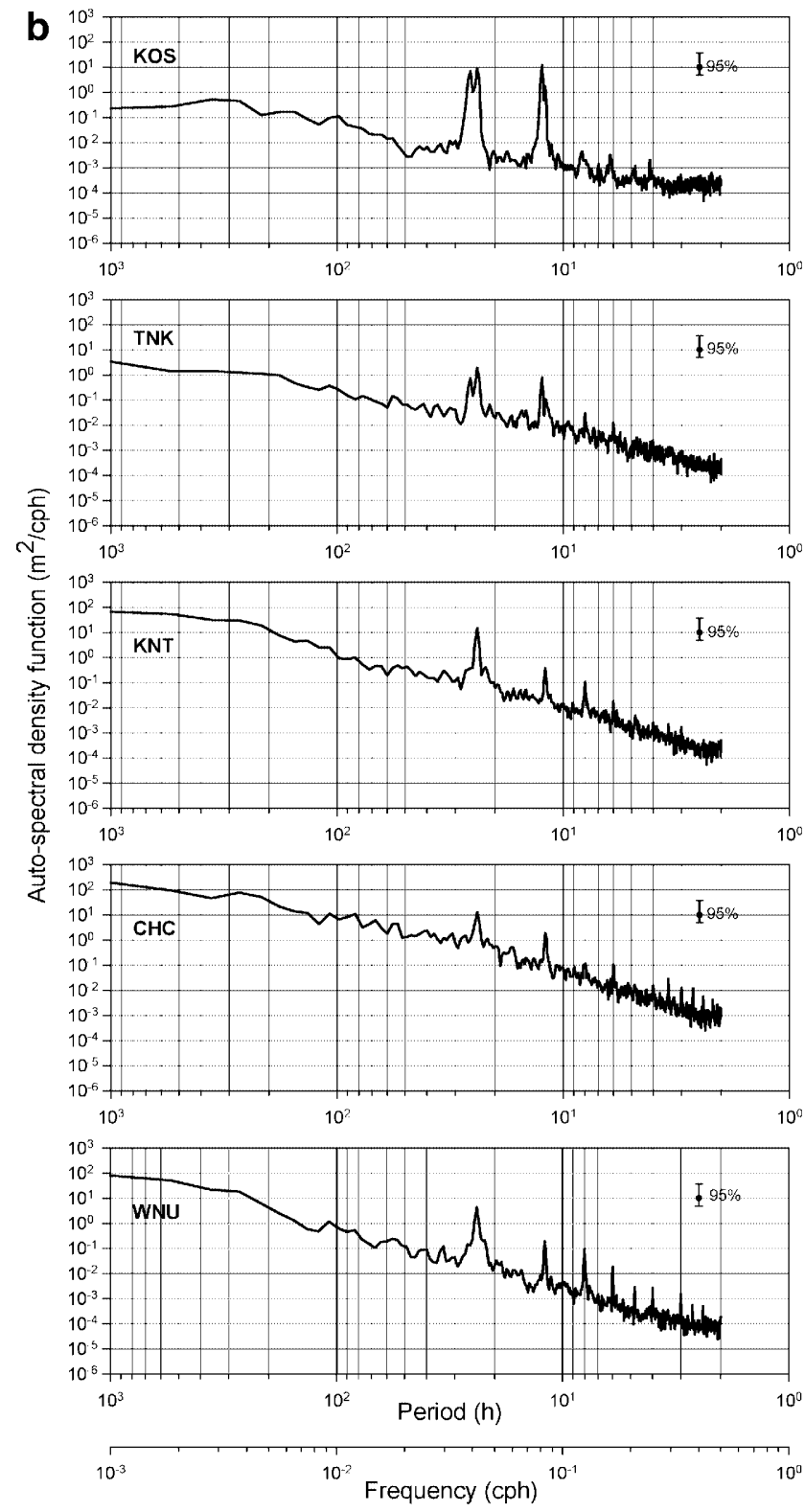

Fig. 3. (Continued)

$G_{x x}=\frac{2}{n_{d} N \Delta t} \sum_{i=1}^{n_{d}}\left|X_{i}\left(f_{k}\right)\right|^{2} ; \quad k=0,1,2, \ldots, \frac{N}{2}$

In order to obtain the cross-spectral density function in frequency domain for two time series, for example $x(t)$ and $y(t)$, the raw estimate of cross-spectral density function for each sub-record is computed through Fourier components $X\left(f_{k}\right)$ and $Y\left(f_{k}\right)$ by using 

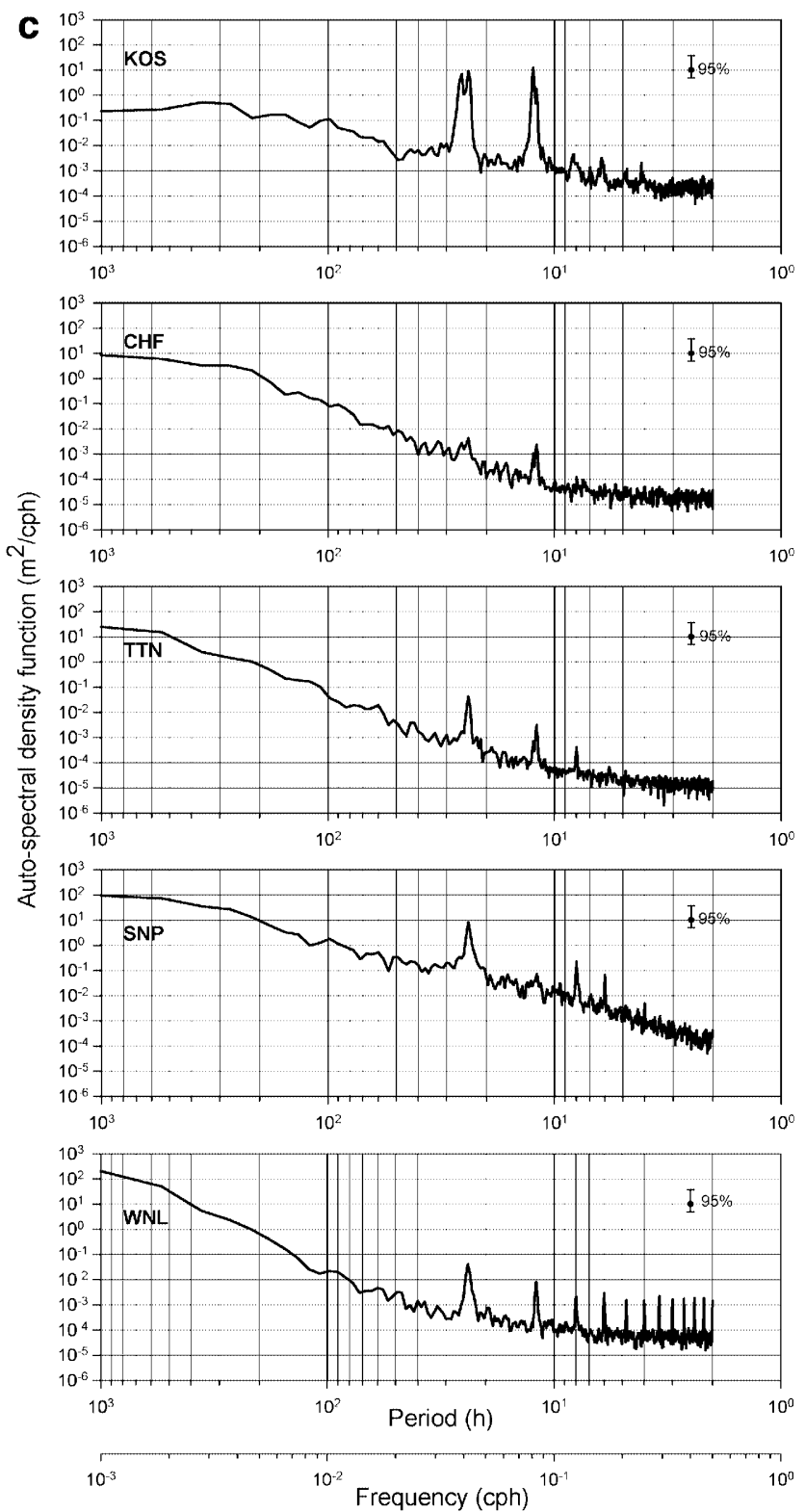

Fig. 3. (Continued)

$G_{x y}=\frac{2}{n_{d} N \Delta t}\left[X^{*}\left(f_{k}\right) Y\left(f_{k}\right)\right]$

where $X^{*}\left(f_{k}\right)$ is the complex conjugate of $X\left(f_{k}\right)$, and $k=0,1,2, \ldots, N / 2$.

As previously mentioned, the smooth estimate of cross-spectral density functions for $n_{d}$ blocks of time series can be expressed as

$\tilde{G}_{x y}\left(f_{k}\right)=\tilde{C}_{x y}\left(f_{k}\right)-i \tilde{Q}_{x y}\left(f_{k}\right)=\left|\tilde{G}_{x y}\left(f_{k}\right)\right| \mathrm{e}^{-i \tilde{\theta}_{x y}\left(f_{k}\right)}$ 

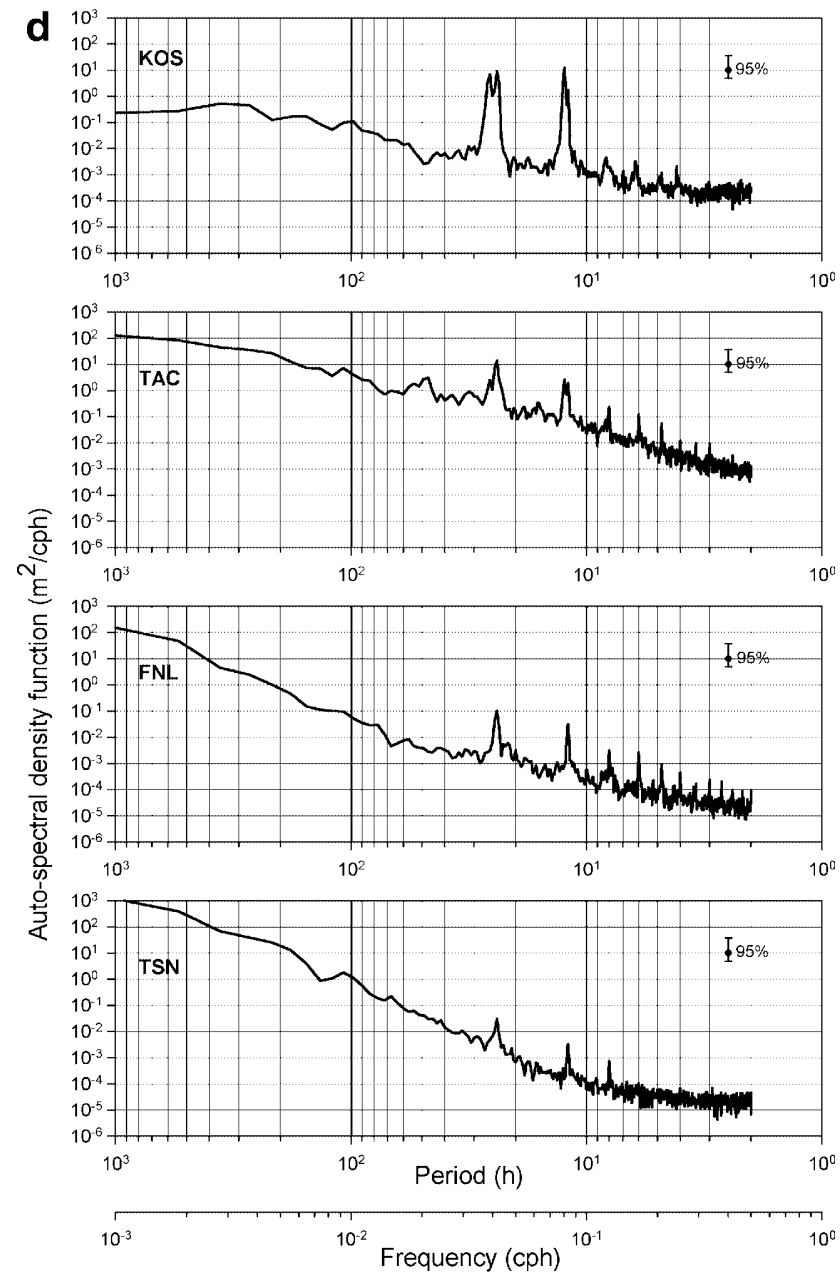

Fig. 3. (Continued)

$\tilde{\theta}_{x y}\left(f_{k}\right)=\tan ^{-1}\left[\tilde{Q}_{x y}\left(f_{k}\right) / \tilde{C}_{x y}\left(f_{k}\right)\right]$

and

$\tilde{\gamma}_{x y}^{2}\left(f_{k}\right)=\frac{\left|\tilde{G}_{x y}\left(f_{k}\right)\right|^{2}}{\tilde{G}_{x x}\left(f_{k}\right) \tilde{G}_{y y}\left(f_{k}\right)}$,

where $\tilde{C}_{x y}\left(f_{k}\right), \tilde{Q}_{x y}\left(f_{k}\right), \tilde{\theta}_{x y}\left(f_{k}\right), \tilde{\gamma}_{x y}^{2}\left(f_{k}\right)$ are co-spectrum, quadrature-spectrum, phase lag and squared coherence, respectively for $k=0,1,2, \ldots, N / 2$.

The autospectral density function using $95 \%$ confidence interval is then given as

$\frac{n \tilde{G}_{x x}\left(f_{k}\right)}{\chi_{n ; 0.05 / 2}^{2}} \leq \hat{G}_{x x}\left(f_{k}\right) \leq \frac{n \tilde{G}_{x x}\left(f_{k}\right)}{\chi_{n ; 1-0.05 / 2}^{2}}$,

where $\chi_{n ; \alpha}^{2}$ is the Chi-square distribution such that probability $\left[\chi_{n}^{2}>\chi_{n ; \alpha}^{2}\right]=\alpha$ for a percentage $\alpha$ with $n$ degree of freedom, $n=2 n_{d}$ (Bendat and Piersol, 1991). 

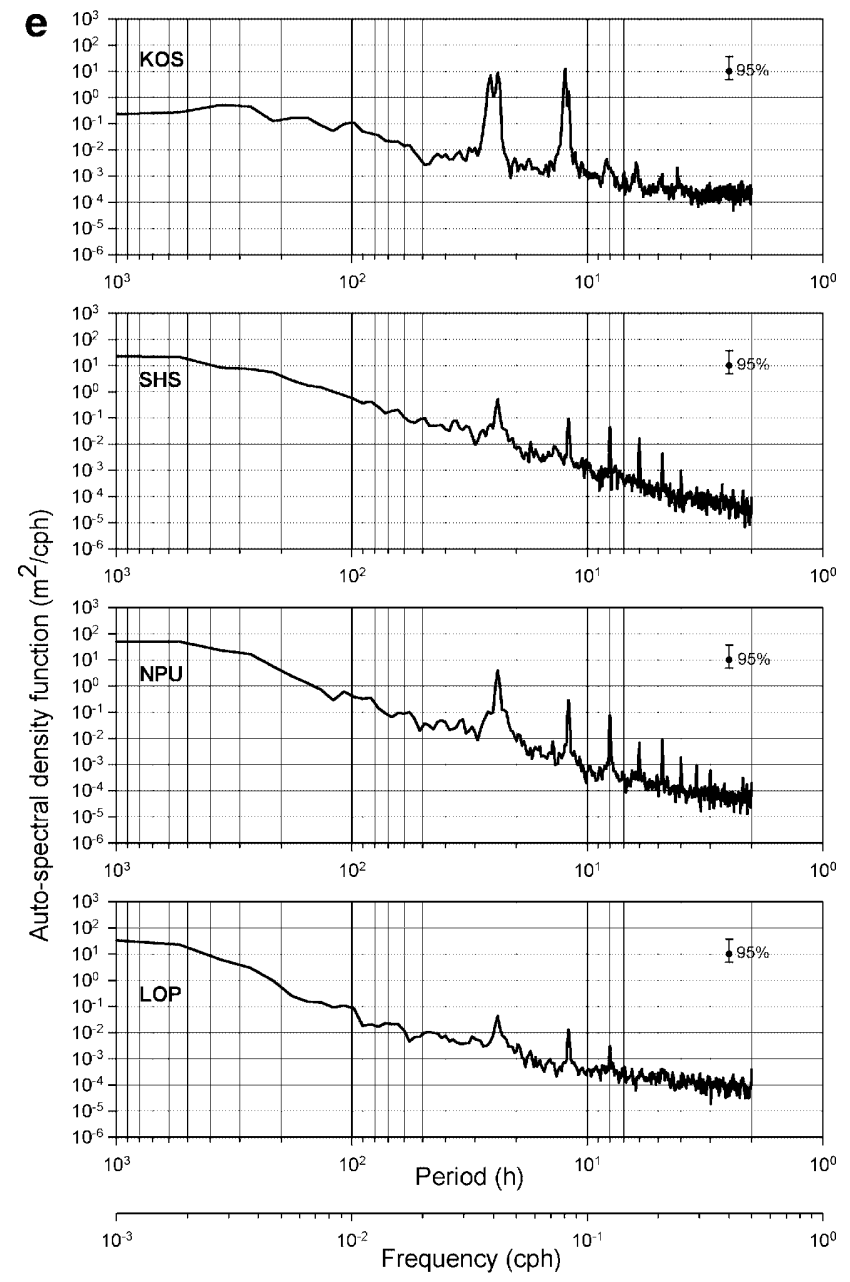

Fig. 3. (Continued)

The coherence with 95\% confidence interval for small random error approximately given by Bendat and Piersol (1991) is then

$$
1-\frac{2 \sqrt{2}\left(1-\tilde{\gamma}^{2}\left(f_{k}\right)\right)}{\left|\tilde{\gamma}\left(f_{k}\right)\right| \sqrt{n_{d}}} \leq \hat{\gamma} \leq 1+\frac{2 \sqrt{2}\left(1-\tilde{\gamma}^{2}\left(f_{k}\right)\right)}{\left|\tilde{\gamma}\left(f_{k}\right)\right| \sqrt{n_{d}}} .
$$

Therefore, the 95\% non-zero coherence significant level (NZC; Shih et al., 1999; Shih, 1999a, b, 2000) is derived as

$\tilde{\gamma}\left(f_{k}\right)=\left|\tilde{\gamma}\left(f_{k}\right)\right|=\frac{\sqrt{n_{d}+32}-\sqrt{n_{d}}}{4 \sqrt{2}}$.

\section{4}

\section{Data analysis}

The water level of sea water gauging station, groundwater well, and atmospheric pressure stations are collected hourly from 1999/02/04 $01 \mathrm{~h}$ to 1999/10/31 $24 \mathrm{~h}$. 

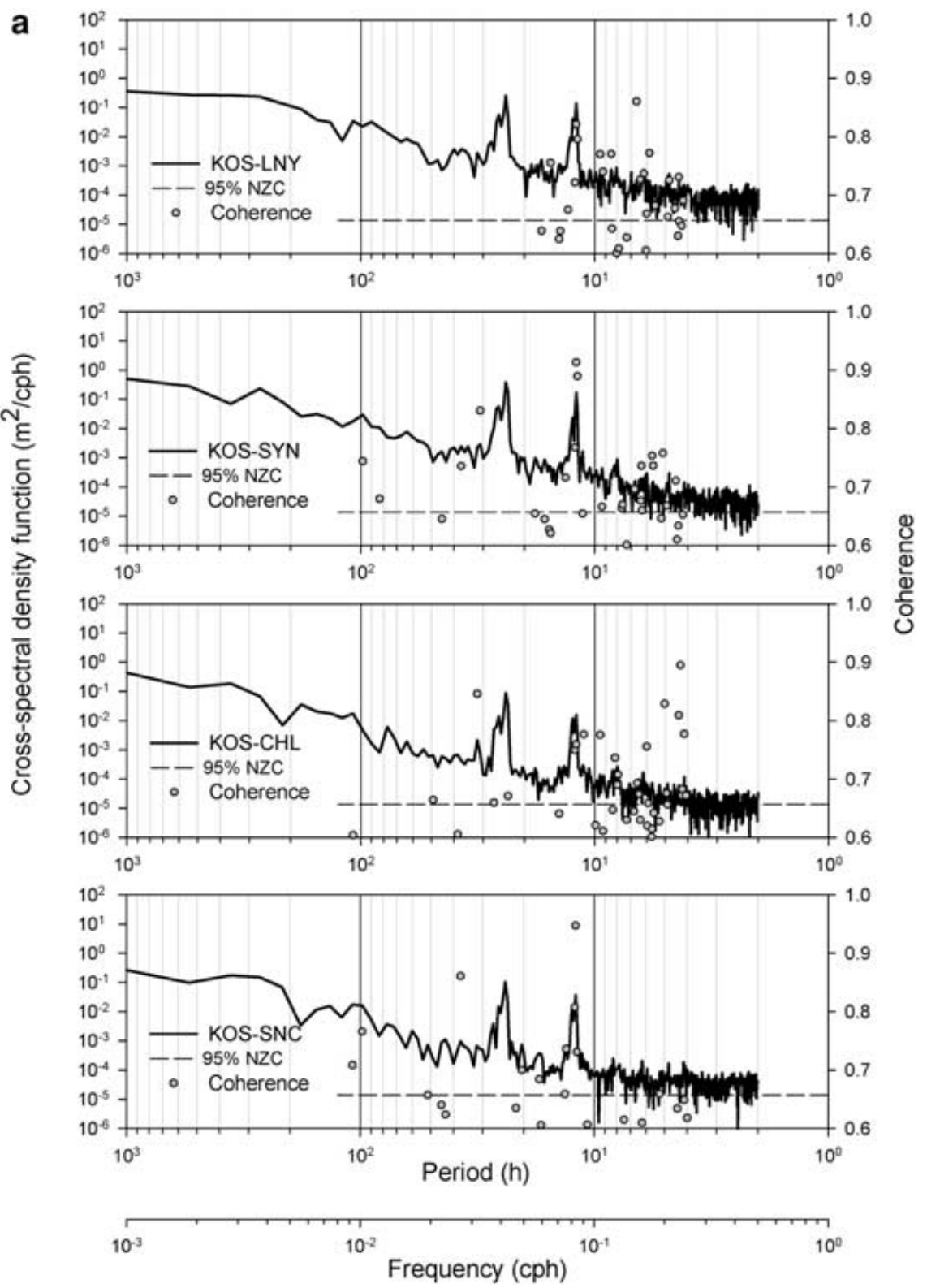

Fig. 4a-e. Cross-spectral density function of groundwater and seawater level. a KOS to LNY, SYN, CHL, SNC. b KOS to TNK, KNT, CHC, WNU. c KOS to CHF, TTN, SNP, WNL. d KOS to TAC, FNL, TSN. e KOS to SHS, NPU, LOP

There are 6480 data points collected at TTN, SYN, CHF, TAC, TNK, LNY, CHL, KNT, SNC, SNP, CHC, SHS, FNL, NPU, WNU, TSN, LOP and WNL for groundwater level measurements, at KOS for seawater level measurements, and at KOSp for atmospheric pressure data (Fig. 1; Table 1). In order to study the extent of atmospheric pressure effect on the water level in groundwater wells and sea water, a comparison of atmospheric pressure with the observed water level in well and sea water gauging station is adopted. The Nyquist frequency is then 
b
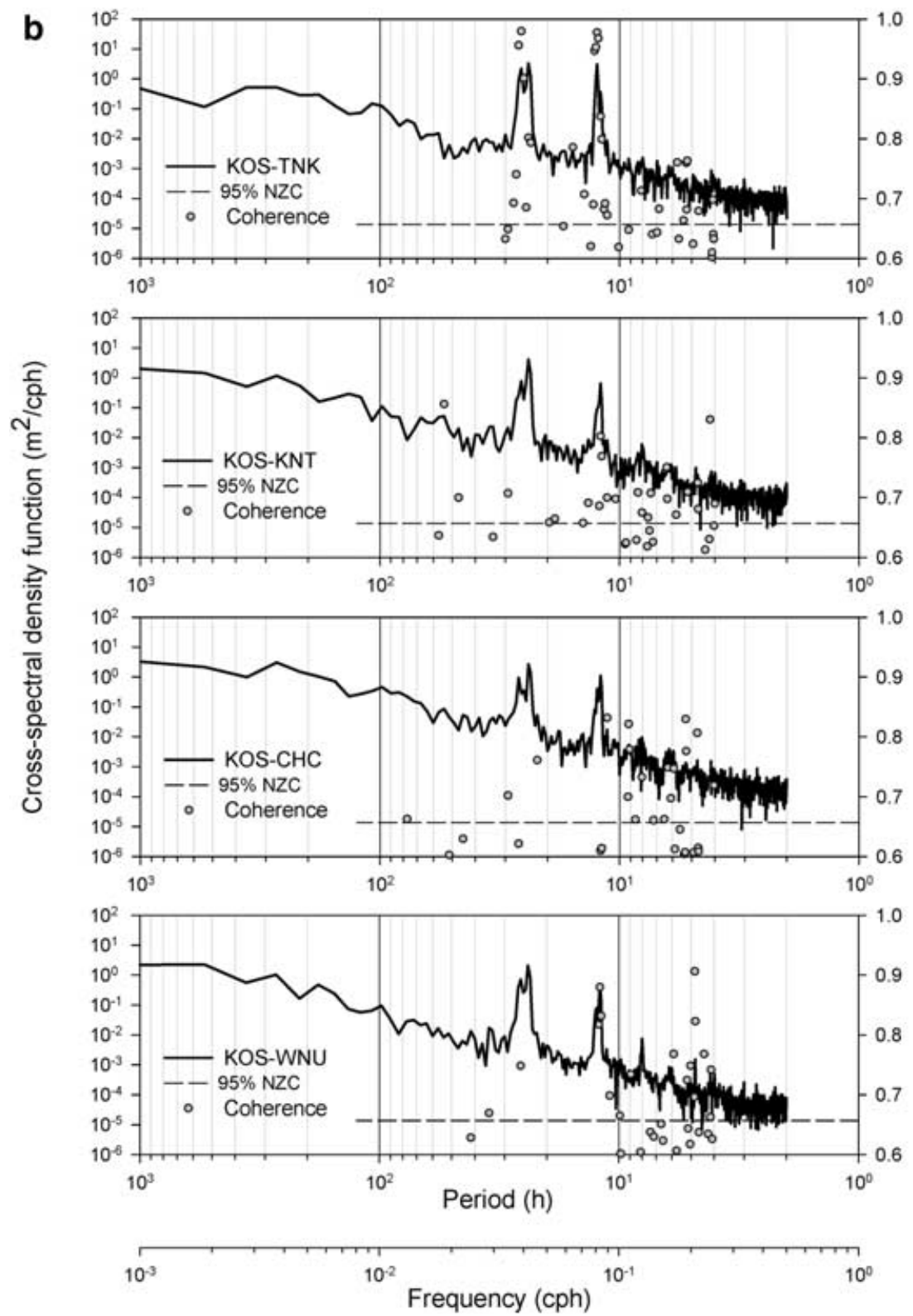

Fig. 4. (Continued)

computed by $1 / 2 \Delta t=0.5$ cycles/hour (cph). In order to reduce random error of estimation of the spectral density function, the data are divided into six subrecords to obtain a smooth estimate by using Eqs. (5) and (6). The sample length for each hourly sub-record is $1080 \mathrm{~h}$ or approximately 45 days. To suppress a leakage problem, the Hanning window is applied for each sub-record (Bloomfield, 1976). By using Fast Fourier Transform, 1080 samples will generate 540 discrete frequencies, of which the resolution of the discrete frequency is $0.92593 \times 10^{-3} \mathrm{cph}$. The autospectral density function of $95 \%$ confidence interval has the lower and the upper extremes of 0.514 and 2.725 , respectively, and the 
C
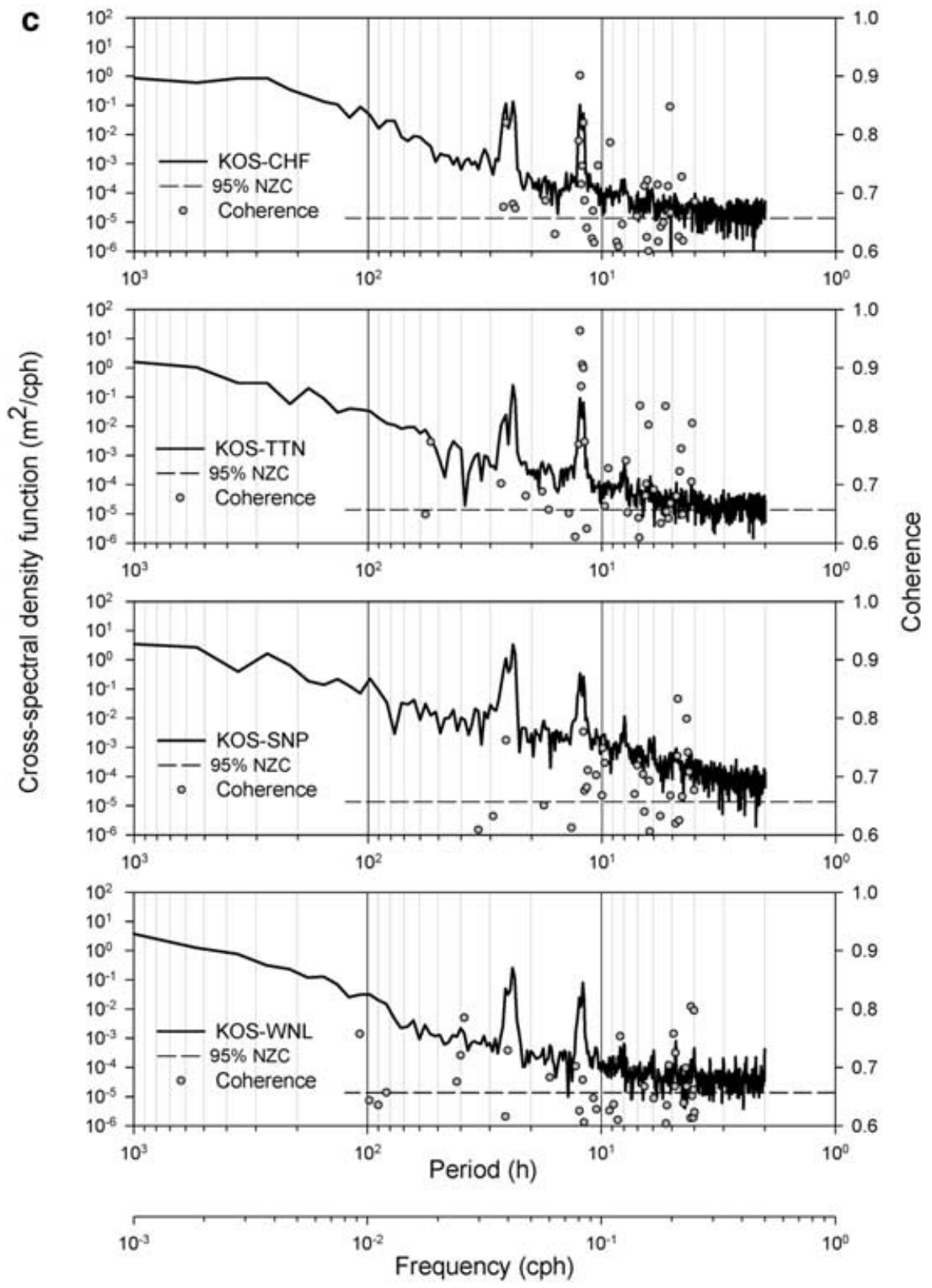

Fig. 4. (Continued)

non-zero coherence significant level (NZC) is calculated to be 0.657 . Although the confidence interval of cross-spectral density function is dependent on coherence at each discrete frequency interval, it is acceptable that the significant peak in cross-spectral density function is evaluated by non-zero coherence rather than by confidence interval. The autospectral and cross-spectral density functions are analyzed and plotted in Figs. 3a-e and 4a-e, respectively. In order to analyze the relationships between atmospheric pressure and water level, the autospectrum and cross-spectrum of atmospheric pressure are computed and shown Fig. $6 \mathrm{a}$ and 


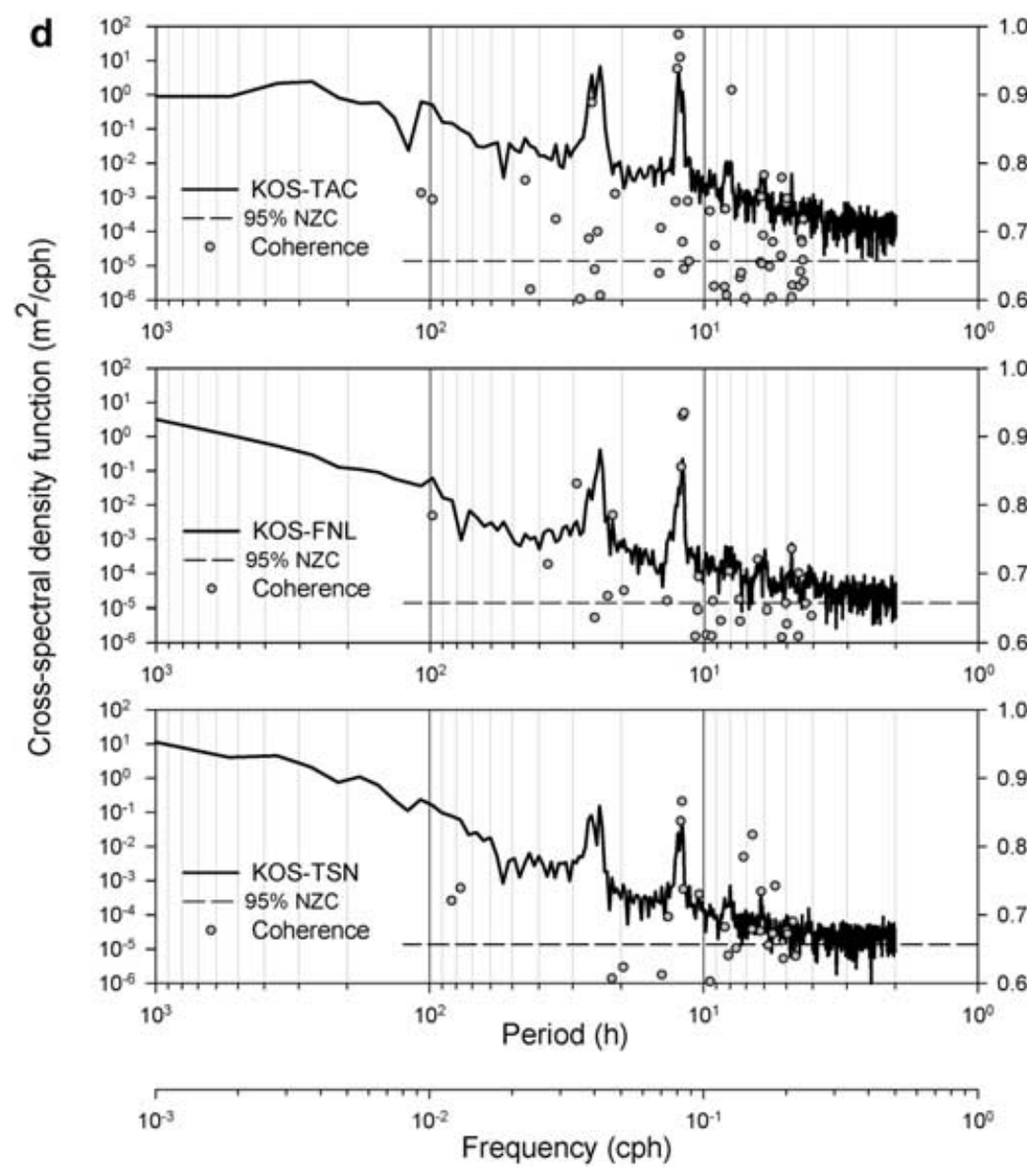

Fig. 4. (Continued)

b. Finally, the phase angle and time lag are discussed to summarize the characteristics of the spectral analysis (Tables 2 and 3, Figs. 7 and 8).

\section{5}

\section{Discussion}

The autospectrum of seawater levels (Fig. 3a) indicates that the distinctive peak in spectrum at frequencies of 0.041667 and $0.08333300 \mathrm{cph}$ are noted with significance over $95 \%$ confidence interval for KOS. These frequencies are related to periods of diurnal $(24 \mathrm{~h})$, semi-diurnal $(12 \mathrm{~h})$, respectively. There are 4 weak peaks at $0.12037,0.16204,0.20463$, and $0.24352(\mathrm{cph})$ with spectrum under $10^{-2} \mathrm{~m}^{2} / \mathrm{cph}$, related to period 8.3077, 6.1714, 4.8869, and 4.1065 (h). For the semi-diurnal component, significant peaks of auto-spectral density function of sea levels at KOS, and groundwater levels at LNY, SYN, SNC, TNK, KNT, CHC, WNU, CHF, TTN, WNL, TAC, FNL, TSN, SHS, NPU, and LOP are discovered (Fig. 3a-e); while CHL, SNC, CHF, TTN, SNP, WNL, TSN, and LOP have weak peak spectrum under $10^{-2} \mathrm{~m}^{2} / \mathrm{cph}$. For the diurnal component, the significant peaks of auto-spectral density function of sea levels at KOS, and groundwater levels at LNY, SYN, CHL, SNC, TNK, KNT, CHC, WNU, CHF, TTN, SNP, WNL, 

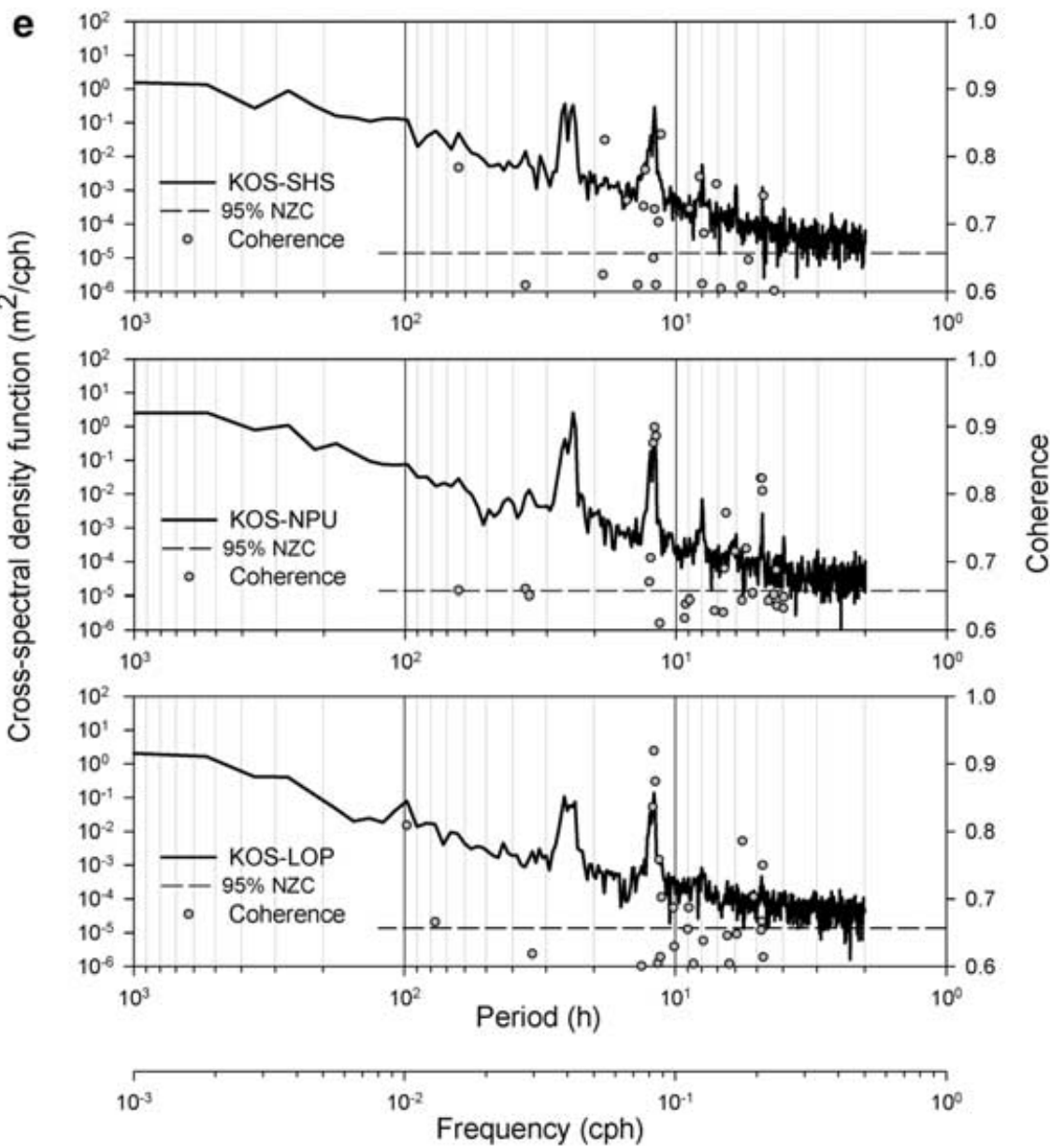

Fig. 4. (Continued)

TAC, FNL, TSN, SHS, NPU, and LOP are discovered (Fig. 3a-e). Among them, the spectrum of groundwater levels at CHL and SNC show weak peak under $10^{-2} \mathrm{~m}^{2} / \mathrm{cph}$. The periods lower than diurnal and semidiurnal components, at 8.3077, 6.1714, 4.8869, and 4.1065 (h), are shown at SYN, WNU SNP, WNL, TAC, FNL, SHS, and NPU. The cross-spectral density function of semi-diurnal components, between pairs KOS to LNY, SYN, SNC, TNK, KNT, WNU, CHF, TTN, WNL, TAC, FNL, TSN, SHS, NPU, and LOP, have significant coherence (exceed NZC) and spectrum (Fig. 4a-e). For diurnal component, spectrums for KOS to LNY, SYN, SNC, TNK, KNT, WNU, CHF, TTN, WNL, TAC, FNL, TSN, SHS, NPU, and LOP, show peaks in cross-spectral density function, but with low level coherence (below NZC).

The variations in atmospheric pressure at ocean surface can induce sea level up or down to a certain degree. The increase in atmospheric pressure will depress water level by approximately $1 \mathrm{~cm}$ per millibar $(\mathrm{mb})$ of pressure change (Gill, 1982). The autospectrum of atmospheric pressure at KOSp shows three distinct peaks to appear at semidiurnal and diurnal frequencies (Fig. 6a). However, the range of pressure changes were within $5 \mathrm{mb}(\approx 5 \mathrm{~cm}$ on oceanic water level $)$ at KOSp pressure station, and the change is considered to be small as compared to 
Table 2. Phase of water level between KOS and groundwater

\begin{tabular}{|c|c|c|c|c|c|c|}
\hline $\begin{array}{l}\text { Frequency } \\
\text { Period }\end{array}$ & $\begin{array}{l}0.041667 \\
24.0000\end{array}$ & $\begin{array}{l}0.083333 \\
12.0000\end{array}$ & $\begin{array}{l}0.120370 \\
8.3077\end{array}$ & $\begin{array}{l}0.162040 \\
6.1714\end{array}$ & $\begin{array}{l}0.204630 \\
4.8869\end{array}$ & $\begin{array}{l}0.243520 \\
4.1065\end{array}$ \\
\hline KOS-LNY & -86.86 & -1.72 & 26.12 & 76.08 & 128.75 & -173.32 \\
\hline KOS-SYN & -45.15 & 93.26 & -21.11 & -84.70 & 34.60 & 24.63 \\
\hline KOS-CHL & 94.62 & 157.29 & -117.31 & -89.81 & -138.25 & -91.93 \\
\hline KOS-SNC & 90.09 & -158.26 & 133.40 & -36.30 & -138.63 & -38.08 \\
\hline KOS-TNK & 20.34 & 38.68 & 106.05 & 53.17 & 28.95 & -116.00 \\
\hline KOS-KNT & -80.76 & -11.07 & 30.15 & 122.07 & 0.20 & 77.57 \\
\hline KOS-CHC & -20.23 & 104.76 & 29.22 & -109.97 & 2.88 & 37.09 \\
\hline KOS-WNU & -100.35 & -128.60 & -6.09 & 10.01 & 53.48 & -174.42 \\
\hline KOS-CHF & 56.80 & 154.27 & 130.90 & -40.46 & 104.98 & -157.47 \\
\hline KOS-TTN & 17.26 & -68.21 & 100.58 & -167.32 & -114.88 & 19.69 \\
\hline KOS-SNP & -106.52 & -107.25 & -29.80 & 35.23 & 90.02 & -128.29 \\
\hline KOS-WNL & -123.72 & -175.14 & 75.16 & 151.16 & -118.80 & 76.19 \\
\hline KOS-TAC & 22.83 & -107.28 & 3.40 & 104.19 & -47.52 & -91.35 \\
\hline KOS-FNL & 77.90 & -155.84 & -96.58 & 34.27 & 36.07 & 83.52 \\
\hline KOS-TSN & -66.09 & -134.25 & 132.11 & 48.50 & -11.16 & -17.83 \\
\hline KOS-SHS & 43.12 & 33.09 & 94.48 & 96.95 & 166.95 & 56.02 \\
\hline KOS-NPU & -54.50 & -99.43 & 64.06 & 29.65 & -97.92 & 139.45 \\
\hline KOS-LOP & -97.50 & -141.96 & 115.97 & -77.96 & 69.33 & -139.77 \\
\hline
\end{tabular}

(Phase: degree; Frequency: cph; Period: hour)

Table 3. Time lag of water level between KOS and groundwater

\begin{tabular}{lrrrrrr}
\hline Frequency & 0.041667 & 0.083333 & 0.120370 & 0.162040 & 0.204630 & \multicolumn{1}{c}{0.243520} \\
Period & 24.0000 & 12.0000 & 8.3077 & 6.1714 & 4.8869 & \multicolumn{1}{c}{4.1065} \\
\hline KOS-LNY & -5.791 & -1.720 & 0.603 & 1.304 & 1.748 & -1.977 \\
KOS-SYN & -3.010 & 3.109 & -0.487 & -1.452 & 0.470 & 0.281 \\
KOS-CHL & 6.308 & 5.243 & -2.707 & -1.540 & -1.877 & -1.049 \\
KOS-SNC & 6.006 & -5.275 & 3.079 & -0.622 & -1.882 & -0.434 \\
KOS-TNK & 1.356 & 1.289 & 2.447 & 0.912 & 0.393 & -1.323 \\
KOS-KNT & -5.384 & -0.369 & 0.696 & 2.093 & 0.003 & 0.885 \\
KOS-CHC & -1.348 & 3.492 & 0.674 & -1.885 & 0.039 & 0.423 \\
KOS-WNU & -6.690 & -4.287 & -0.141 & 0.172 & 0.726 & -1.990 \\
KOS-CHF & 3.787 & 5.142 & 3.021 & -0.694 & 1.425 & -1.796 \\
KOS-TTN & 1.151 & -2.274 & 2.321 & -2.868 & -1.560 & 0.225 \\
KOS-SNP & -7.101 & -3.575 & -0.688 & 0.604 & 1.222 & -1.463 \\
KOS-WNL & -8.248 & -5.838 & 1.734 & 2.591 & -1.613 & 0.869 \\
KOS-TAC & 1.522 & -3.576 & 0.079 & 1.786 & -0.645 & -1.042 \\
KOS-FNL & 5.194 & -5.195 & -2.229 & 0.588 & 0.490 & 0.953 \\
KOS-TSN & -4.406 & -4.475 & 3.049 & 0.832 & -0.152 & -0.203 \\
KOS-SHS & 2.875 & 1.103 & 2.180 & 1.662 & 2.266 & 0.639 \\
KOS-NPU & -3.634 & -3.314 & 1.478 & 0.508 & -1.329 & 1.591 \\
KOS-LOP & -6.500 & -4.732 & 2.676 & -1.337 & 0.941 & -1.594 \\
\hline
\end{tabular}

(Time lag: hour; Frequency: cph; Period: hour)

the fluctuation of sea level and that of water level in some of groundwater wells (Fig. 5), although the spectral peaks (Fig. 6a) and high coherence (Fig. 6b) are noted in atmospheric pressure, sea level, and groundwater level for semidiurnal and diurnal components. 


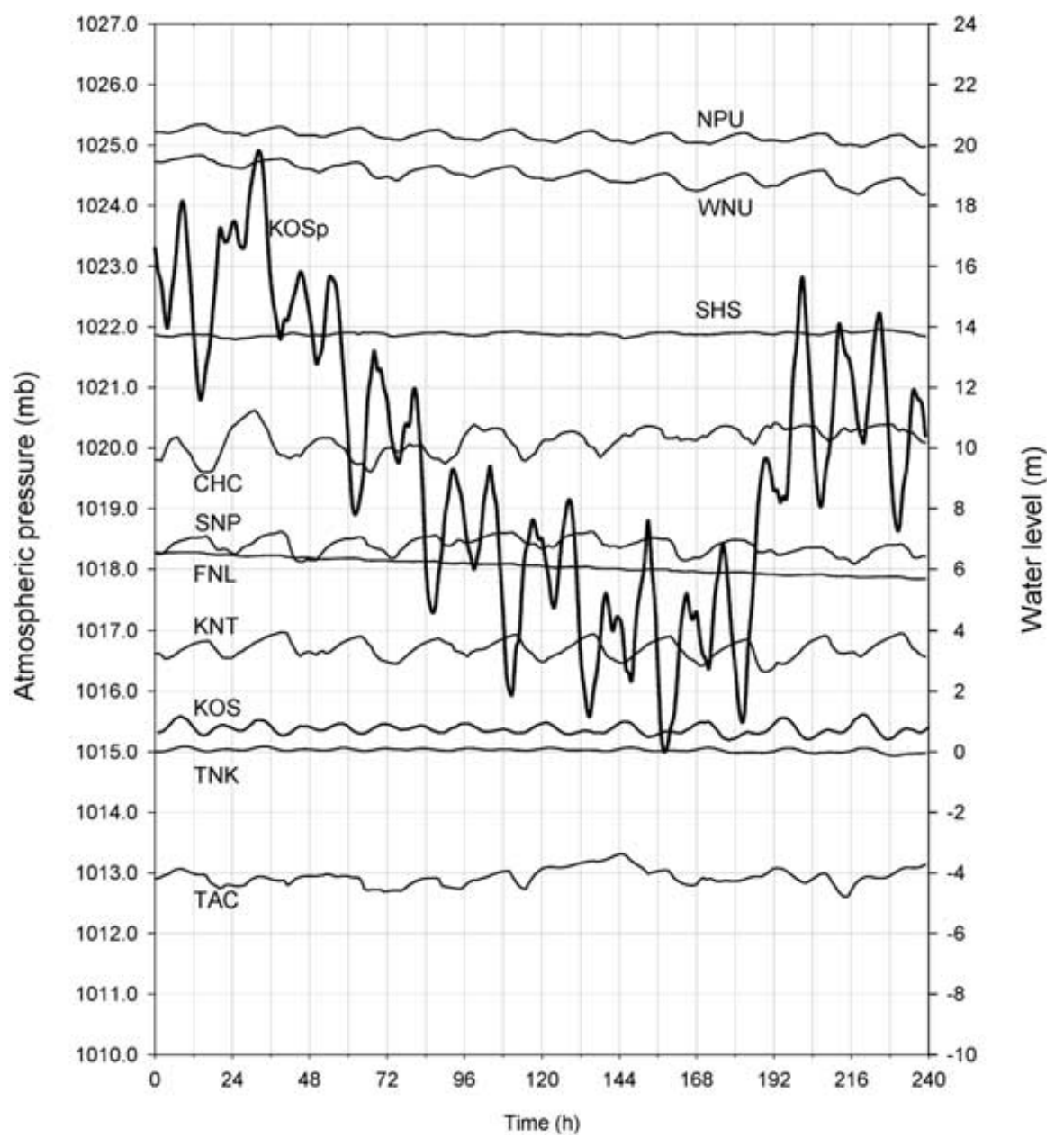

Fig. 5. Time series of atmospheric pressure and water level

The semidiurnal signals are discovered with high coherence between water level and atmospheric pressure at KOSp (Fig. 6b). The similar phenomena are clearly correlative between atmospheric pressure and groundwater level for some stations (Fig. 6b). The variations in time series of atmospheric pressure, seawater level, and groundwater level seem to be in a similar fluctuation pattern (Fig. 5). Furthermore, from time series observation, the phase of atmospheric pressure at KOSp is in phase with water level fluctuation of groundwater well at NPU, WNU, SHS, CHC, SNP, FNL, KNT, TNK and TAC, and seawater at KOS (Fig. 5). It is suggested that pressure variations do not significantly affect sea water and groundwater level but probably dominated by astronomical tidal effect in KOS.

Godin (1972) reports that the astronomical tides for semidiurnal $M_{2}$ and diurnal $M_{1}, S_{1}$, and $K_{1}$ tides are at frequencies $0.08051,0.04027,0.04167$, and $0.04188 \mathrm{cph}$, respectively. From the above-mentioned results of spectral responses, the astronomical tidal components may be the main factor causing fluctuations in both sea water and groundwater levels. To further study the actual astronomical tidal components, a harmonic analysis and longer time series are recommended to be adopted in the future. 

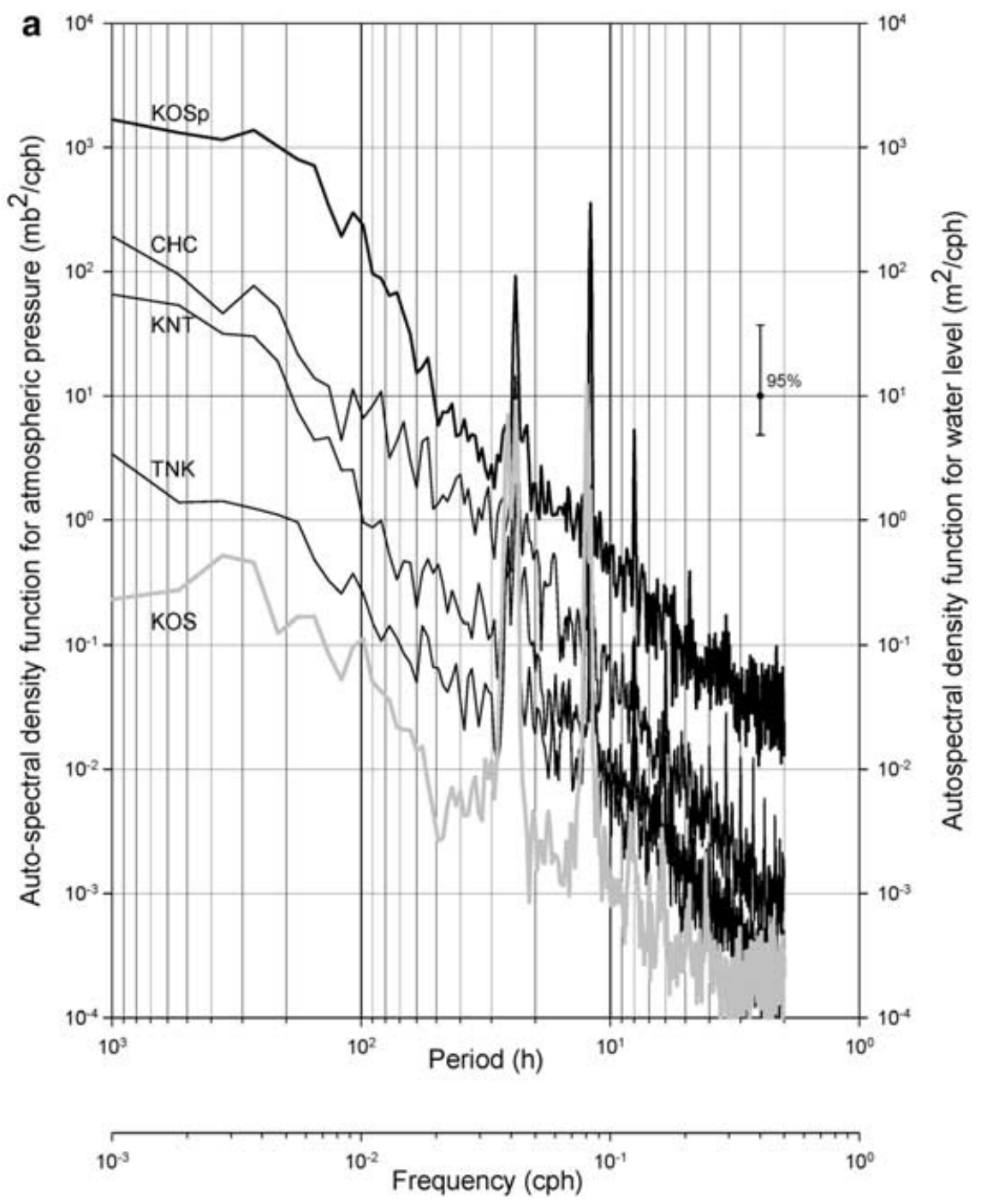

Fig. 6. a Auto-spectral density function of atmospheric pressure, groundwater and seawater level (KOSp, CHC, KNT, TNK, KOS). b Cross-spectral density function between atmospheric pressure and water level (KOSp to KOS, CHC, KNT, TNK)

The phase and time lag for water level at KOS to groundwater level are shown in Fig. 7, Table 2 and Fig. 8, Table 3. For semi-diurnal component, the maximum and minimum time lag is 5.838 and $0.369 \mathrm{~h}$ for WNL and KNT (Table 3), respectively. Both WNL and KNT lead KOS for semi-diurnal component (Table 2). For different phase and time lag distribution, such relationship is resulted from the fact that the groundwater flowing through the aquifer is dominated by characteristics of the aquifer matrix. Time lags are estimated from twenty minutes to a few hours in aquifers.

From the above analysis, the groundwater level in the coast of the study area fluctuated in a similar pattern with astronomical tide. Therefore, by assuming that the external disturbance can affect the groundwater fluctuation, the aquifer characteristics must be the one to dominate the change in amplitude. The purpose 
b
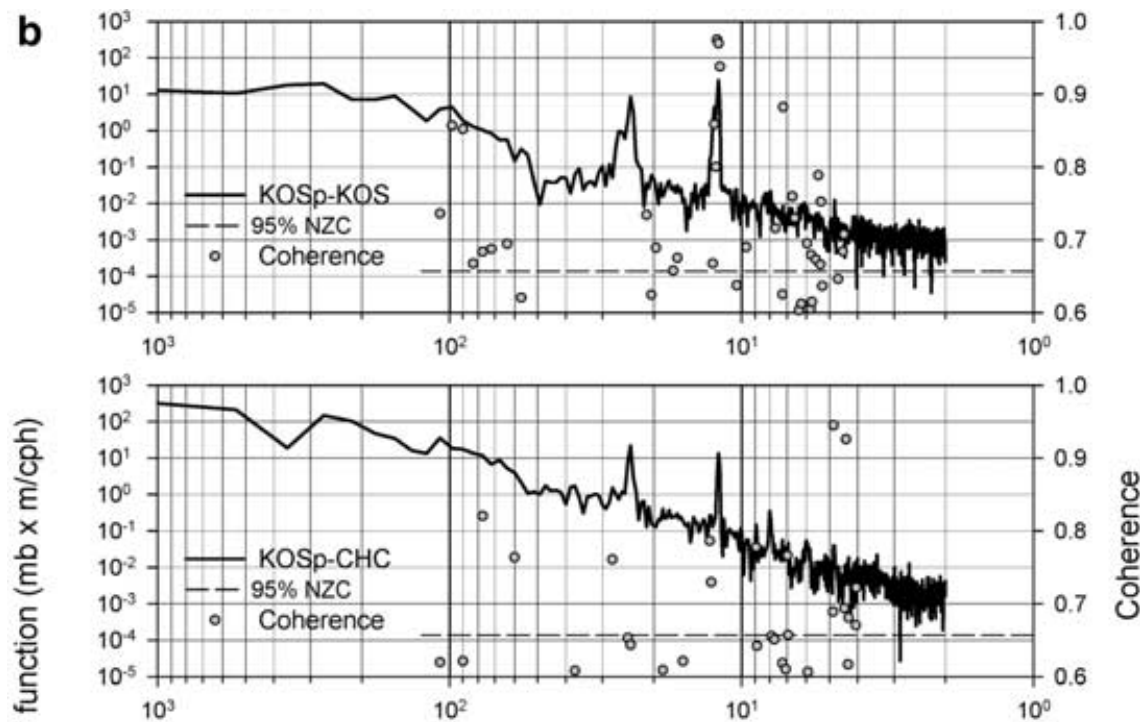

흥
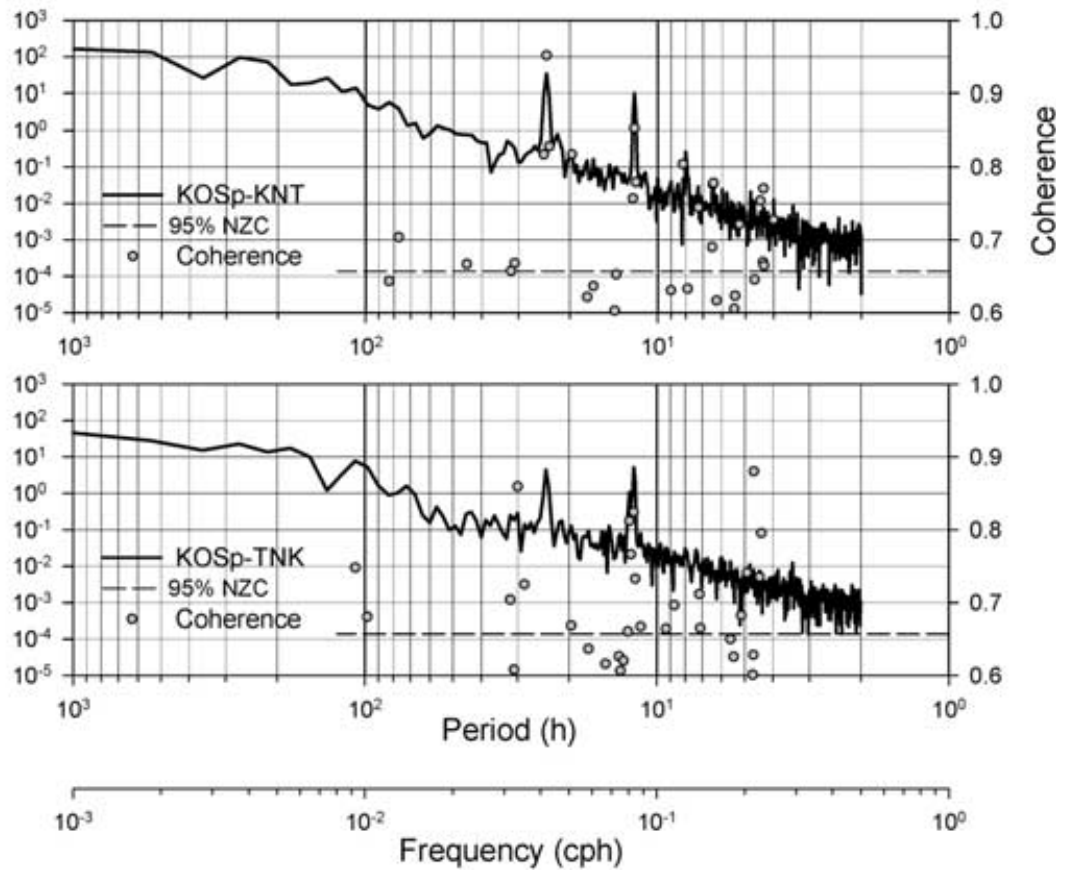

Fig. 6. (Continued)

of this study is to evaluate the general characteristics of groundwater fluctuation by spectral analysis and to explore the relationship between frequency and amplitude variation caused by the water level fluctuation in southwestern Taiwan. This study demonstrates in a fact that spectral analysis is a useful method to study periodical fluctuation of groundwater and tidal water.

6

\section{Conclusion}

Water level of seawater gauging station and eighteen groundwater wells in southwestern Taiwan are analyzed by using spectral analysis in time and 


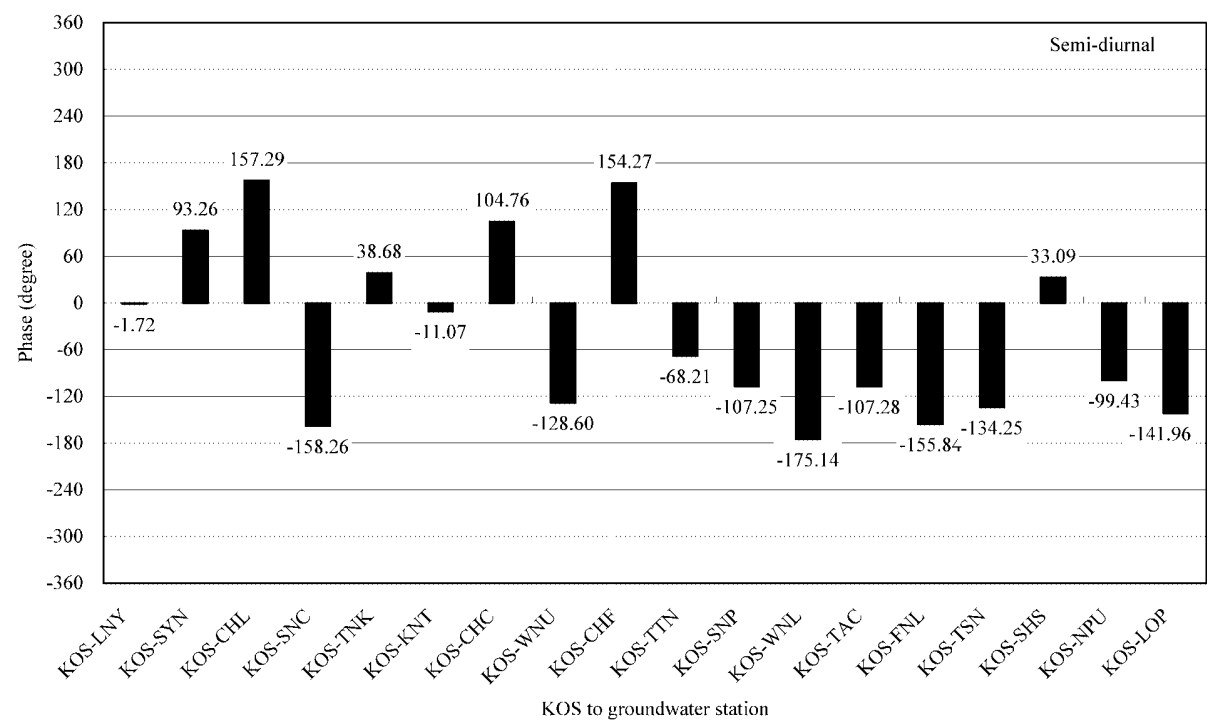

Fig. 7. Phase of water level between seawater at KOS and groundwater for semi-diurnal component

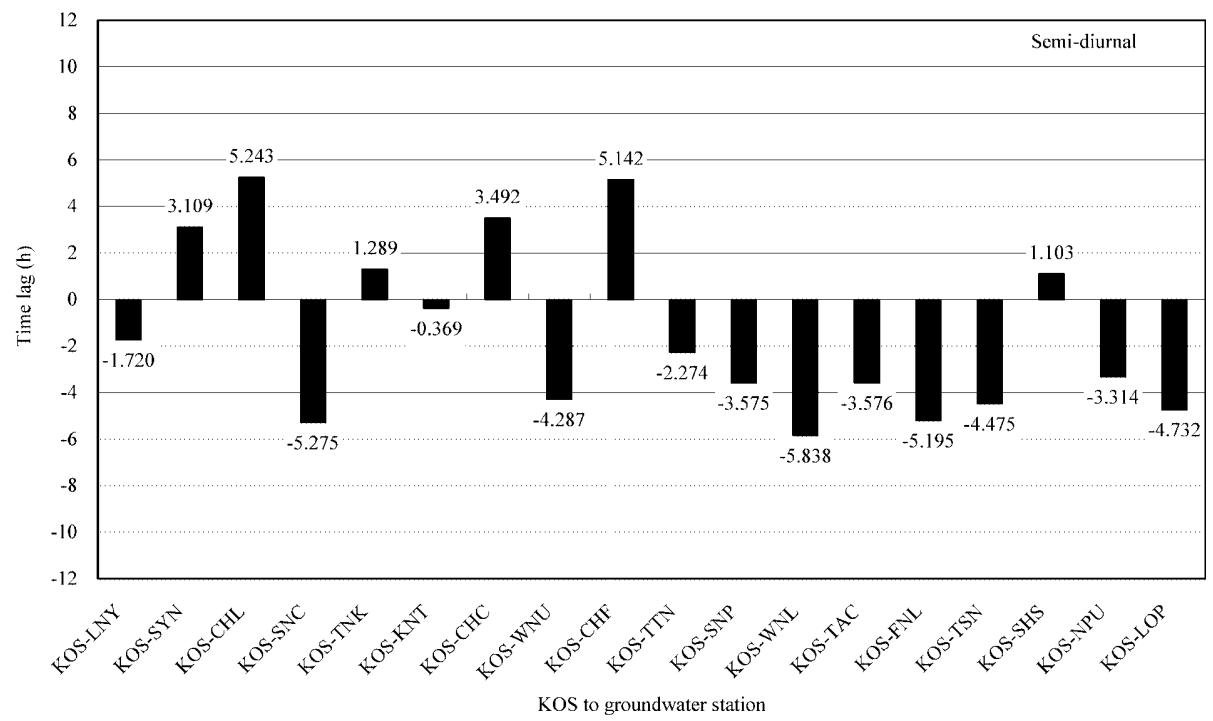

Fig. 8. Time lag of water level between seawater at KOS and groundwater for semi-diurnal component

frequency domain. The autospectral and cross-spectral density function, coherence, phase angle, and the associated statistic parameters are studied through 270 days of hourly data collected. The semidiurnal component is found to be the most significant signal from the measurement of water level and atmospheric pressure, and the diurnal component is less distinctive in part of water level and atmospheric pressure record. Although auto-spectral and cross-spectral density functions are significant in atmospheric pressure and water level, the pressure 
variations do not significantly affect the seawater and the majority of groundwater level in the study area from amplitude of time series observations. It concludes that astronomical tidal components are likely to be the main factor causing seawater and groundwater level to fluctuate in Pingtung, Taiwan. The time lags are estimated from 20 min to a few hours in aquifers. In this study, the spectral analyses of water level in time and frequency domains give strong indications of sensitive variations to water level fluctuation.

\section{References}

Bendat JS, Piersol AG (1991) Random Data, Analysis and Measurement Procedures. John Wiley, pp. 566

Bloomfield P (1976) Fourier Analysis of Time Series: an Introduction. John Wiley, pp. $80-87$

Chinese Navy Chart (1995) No. 04504

Gill AE (1982) Atmospheric-Ocean Dynamics. Academic Press, p. 337

Godin G (1972) The Analysis of Tides. University of Toronto Press, pp. 232-233

Shih DC-F, Chiou KF, Lee CD, Wang IS (1999) Spectral responses of water level in groundwater and tidal river. Hydrol. Processes 13(6): 889-911

Shih DC-F (1999a) Determination of hydraulic diffusivity of aquifers by spectral analysis. Stochastic Environ. Res. Risk Assessment 13(1/2): 85-99

Shih DC-F (1999b) Inverse solution of hydraulic diffusivity determined by water level fluctuation. J. Amer. Water Resour. Assoc. 35(1): 37-48

Shih DC-F, Lee C-D, Chiou K-F, Tsai S-M (2000) Spectral analysis of tidal fluctuations in groundwater level. J. Amer. Water Resour. Assoc. 36(5): 1087-1100 